\title{
EL RECURSO AL SANTORAL EN CASTILLA, DEL BARROCO A LA ILUSTRACIÓN, 1650-1834*
}

\author{
POR \\ Máximo García Fernández \\ Universidad de Valladolid
}

\begin{abstract}
RESUMEN
Las manifestaciones más nítidas de la mentalidad castellana durante el Antiguo Régimen se relacionaban con la religiosidad colectiva y con la salvación eterna. Así, la abogacía mariana era invocada frecuentemente y siempre todos requerian la ayuda del santoral.

La importancia de las obras artísticas de contenido sacro, el peso de la onomástica y el continuo recurso a la corte celestial, en especial a la Virgen María, muestran la obligatoriedad de la solicitud de intercesión sobrenatural ante la fuerte necesidad de protección.

La comparación de ámbitos urbanos y rurales, tras el estudio de diez mil testamentos y quinientos inventarios y particiones de bienes, permite advertir las permanencias y las transformaciones de múltiples rituales de la piedad popular desde la época barroca hasta el inicio de la ruptura de los valores sobre los que se sustentaba.
\end{abstract}

\section{Abstract}

The clearest manifestations of the castilian mentality during the Ancien Regime were related with the collective religiosity and the etemal salvation. Marian help was frecuently invoked and all the people always requeried Saints' aid.

* Una primera reflexión sobre este tema, con el título: "La Advocación Mariana y el Recurso al Santoral en Castilla durante el Antiguo Régimen", fue presentada a la Sección B: Mentalidad e Ideología en el Antiguo Régimen, de la Il Reunión Científica de la Asociación Espaftola de Historia Moderna, celebrada en Moratalla (Murcia) entre el 28 y 30 de abril de 1992. Por distintas razones, no pudo ser inclúfdo en las Actas que han sido publicadas bajo el título: Mentatidad e ldeología en el Antiguo Régimen, —vol. II- (Murcia, 1993). 
The importance of the holy works of art, the weight of the personal names and the continuous resort to the celestial court, especially to the Blessed Virgin show that it was compulsory to request the supematural mediation in ocasions when someone needed protection.

We can observe the permanences and the changes of numerous rituals of the popular piety from the Baroque times to the beginning of the nupture of the values which supported it tharks to the comparation of rural and urban areas and to the study of 10.000 wills and 500 inventories and partitions.

Entre las manifestaciones más nítidas de las mentalidades castellanas de Antiguo Régimen resaltan las relacionadas con la religiosidad colectiva. Las referencias trascendentes se constituyeron en componentes claves de la vida popular; vida siempre orientada y que tenía como punto neurálgico el fin último para el cual fue creado el hombre: la salvación eterna.

La cotidianidad de tales referencias supraterrenales motivaba que muchas expresiones habituales estuvieran cargadas de un contenido de vinculación estrecha con el mundo celestial.

Muchos de los títulos de los libros coleccionados en las bibliotecas, el asociacionismo gremial y en cofradías, los motivos del calendario festivo, los días elegidos para la celebración de misas perpetuas, la propia denominación de los ciclos "pretridentinos de misas", la localización de los lugares de sepulturación y los enterramientos "en sagrado", las preferencias conventuales a la hora de señalar el último lugar de reposo, las festividades en las que oficiar misas postmortem o la elección de mortajas concretas, las referencias religioso-celestiales en los encabezamientos testamentarios... convergen hacia un mismo punto: la solicitud de intercesión celestial ante una fuerte necesidad de protección.

Además de hacer hincapié en todos estos aspectos claves, centraremos este análisis en otros dos parámetros de religiosidad capitales en la mentalidad de la época: la importancia de las obras artísticas de contenido sacro y el peso de la onomástica.

En definitiva, el continuo recurso a la corte celestial, en especial a la Virgen María, constituía una necesidad-obligación universal para el castellano durante la Edad Moderna.

La protección, abogacía, presencia e intercesión mariana y del santoral eran invocadas tan frecuentemente que en bocas, paredes, actas notariales, nombres propios y mas en el momento crucial de la muerte, el amplio repertorio de mediadores celestes, en una clara jerarquización de poder escatológico-y de relieve de ciertas órdenes conventuales (la franciscana, básicamente)--, siempre estaban presentes. 
Estas ideas, en su evolución histórica y confrontando ámbitos urbanos y rurales, se desprenden del estudio de más diez mil testamentos y quinientas escrituras de inventariado, tasación y partición de bienes. Tanto en Valladolid como en muchas de las localidades de su entorno se advierten ciertas transformaciones desde la época barroca hasta la ruptura de los valores antiguorregimentales durante el siglo XIX, pero también la permanencia de múltiples manifestaciones de la piedad colectiva anterior ${ }^{1}$.

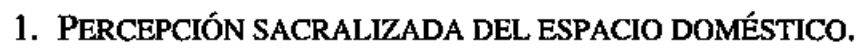

Los ámbitos privados contaban siempre con referencias religiosas. Advocaciones marianas y un amplio catálogo del santoral recubrían las viviendas. Sus moradores se sentían así "vigilados y proțegidos" por abogados universales y devociones particulares. Era una plasmación pictórica de la presencia continuada de lo sobrenatural, y que definía las mentalidades.

La cotidianidad de lo sacro entre los pucheros recordaba al ser humano la vida del más allá. Ánimo de protección que no se perdió, como se desprende del análisis de su evolución temática durante el Setecientos ilustrado. Era, por tanto, una sociedad que deseaba tener cerca y propicios a los medianeros celestiales: protegida por la atenta mirada divina. Una población muy devota de la imaginería sagrada, al haber extendido la Iglesia el culto "milagrero" hacia el santoral, donde cada enfermedad, oficio o cualquier aspecto de la vida contaba con su santo protector o la advocación mariana más apropiada y "de garantía".

Aunque la media vallisoletana de obras de arte por inventario se situaba en 33 piezas, las diferencias entre cada hogar eran abismales. También su valor metálico. El ejemplo de Medina de Rioseco puede generalizarse: de 32 obras - como media - por unidad familiar (descendente desde mediados del siglo XVIII), la gran mayoría aparecían en las pocas viviendas de quienes poseían más de cien (un 5\%); y sólo un $8,3 \%$ en el $32,5 \%$ de las moradas con menos de quince: ocho pinturas era la norma en una tercera parte de las casas castellanas.

Estancias principales y habitaciones de muchas viviendas se constituían en centros de exposición pictórica; también otros recintos (cocinas, zaguanes,

1 Para analizar cormo un espacio adecuado para vivienda familiar se convertía a Ia vez en "espacio sacralizado", hemos extraído todas las referencias artístico-religiosas aparecidas en las escrituras testamentarias e inventarios post-mortem recogidos en el Archivo Histórico Provincial de Valladolid (A.H.P.V.) y protocolizados durante 1650-654, 1700-701, 1750-754, 1795-799 y 1830-834 en la ciudad de Valladolid y otras localidades de su entomo rural provincial: Medina de Rioseco, Medina del Campo, Tordesillas, Olmedo, Pefhatiel, Curiel, Iscar, Portillo, Cigales, la jurisdicción de Valladolid y la de Cevico de la Torre (Palencia). 
pasillos...) podían contar con ellas. La universal presencia de lo sagrado era perenne en toda la casa, porque la importancia absoluta de las obras de carácter religioso es innegable. Junto a ellas, otras pinturas, tapices y doseles con temática floral-campestre o mitológico-clásica marcaban las diferencias económicas y hereditarias. Varios inventarios de Medina de Rioseco señalaban la distribución de los objetos por "salas"; una de sus casa, hacia 1704, repartía así su mobiliario pictórico:

"Sala principal: una pintura de Nuestra Señora del Rosario; una de San Ildefonso; una del Santo Cristo de Burgos y otra de Nuestra Sefiora de la Soledad; siete relicarios grandes con vitelas, vidrieras y marcos, cuatro pequeños y seis de seda; una hechura de Nuestra Señora de la Soledad; una de la Virgen y el Niño y un dosel con dos relicarios de seda. Sala segunda: una pintura de Nuestra Señora de la Leche; una de Nuestra Señora de Belén; una de Nuestra Señora de la Soledad; una de la Visitación de Nuestra Señora a Santa Isabel; una de San, Pedro apostol, una de San Gregorio; una de la Resurrección del Señor, una de Nuestra Señora y el Niño; dos pequefias en tabla del Esposo y la Esposa; y otra de Nuestra Señora del Rosario; más dos tarjetas; dos relicarios con vidrieras y marcos; una talla de Nuestra Señora de la Concepción; un dosel con la hechura de un Santo Cristo en la cruz y un país con la Historia de Adán y Eva. En la cocina pendían cuatro pinturas de diferentes Santos en bastidor. En otras estancias: cinco tapices de montería grandes y otros tres pequeños (valorados en 600 reales); otros dos tapices grandes de flores con escudo de armas; y en plata: una pila de agua bendita con la hechura de Nuestra Señora de la Concepción; otra pila con una cruz; una cruz de Caravaca con la hechura de un crucifjo (143 rls.); un relicario con la hechura de Nuestra Señora de Copacabana; un rosario con cruz y medallas; y una encomienda de San Pedro Mártir de oro"2.

2 A.H.P.V., Secc. Prot., Leg. 9221, ff. 393 y ss.. Otros ejemplos elocuentes podrían traerse a colación. Además de las existentes en la sala principal, María de Belbis tenía diez pinturas ordinarias de la calle Santiago en el "cuarto bajo"; A.H.P.V., Secc. Prot., Leg. 9101, ff. 709-734 (Medina de Rioseco, 1702). Otra riosecana dedicada a la venta de géneros de ropería, "en el cuarto junto a la sala": una pintura del Salvador, una de San Juan, una de la Verónica, una de Nuestra Señora de la Piedad, una de Nuestra Señora del Rosario y una áltima de María; y en el "lecho": un dosel de lienzo pintado con una pila de latón y otro con ura hechura del Santo Cristo; A.H.P.V., Secc. Prot., Leg. 9446, ff. 342 y ss. (1704). El "cuarto segundo" de Manuel Fernández Santos se adomaba con: catorce pinturas ordinarias de la calle Santiago, una hechura del Niño Jesús de bulto con peana y una pila de latón de agua bendita; A.H.P.V., Secc. Prot., Leg. 9446, ff. 382-434 (Medina de Rioseco, 1702). Por áltimo, además de las 32 piezas de la sala principal, D' María Vázquez de Prada, viuda de un capitán de caballería, contaba en su "antesala" con: tres pinturas en papel con marcos, dos vitelas con marcos, una pintura de Nuestra Señora del Popolo, cuatro pinturas ordinarias de la calle Santiago de diferentes Santos, dos relicarios pequeños, otro con vidrieras, dos Lignum Crucis pequefios, un Agnus Dei con vidrieras, un rosario de Coco con cruz y medallas, otro de ámbar, un relicario de nácar y otro de Nuestra Senfora de la Soledad con vidrieras; en la "cocina" tenía ocho países fruteros; y en el "cuarto junto a la cocina": una pintura de Nuestra Señora de la Concepción y otra de San Nicolás; A.H.P.V., Secc. Prot., Leg. 9220, f. 512 (Medina de Rioseco, 1702).

Aficiones y devociones en el antiguo régimen

Hispania Sacra 50 (1998) 
Se adquirieron nuevas obras pictóricas, como demuestra el laboreo constante del taller vallisoletano de estampación y venta sito en la calle Santiago: eran productos demandados y ampliamente satisfechos. Así, un lagunense, allá por 1700 , debía a cierto pintor nada menos que 70 cuadros y 48 "tablillas", compradas a cuatro cuartos y medio cada una ${ }^{3}$.

No obstante, mediante el reparto de hijuelas, pasando de generación en generación (como ropas y otros útiles), se adomaban muchas viviendas4: mansiones de abolengo y estancias que hoy costaría denominar casas ${ }^{5}$. Aunque no fueron los únicos ${ }^{6}$, los miembros del clero, como poseedores destacados de

3 A.H.P.V., Secc. Prot, Leg. 12344, sin fol. (Laguna de Duero, 1701).

4 Baste señalar cómo, cuando cada cónyuge enumera los enseres que aporta al matrimonio, el capital de Diego Vázquez ascendía a 1.398 rls., detallando una pintura del Santo Cristo, séis cuadros diferentes y una hechura de un Santo Cristo en la cruz, (51 rls.); y dentro de la dote de su esposa, Elena de Ocasal, una hechura de San José con marco, una de Nuestra Señora de la Concepción y otra de San Cayetano, más una pintura de Nuestra Señora de la Soledad, una de San Francisco y otra de un Ecce Homo (76 rls. de los 2.033 rls. a que ascendía completa); A.H.P.V., Secc. Prot., Leg. 9173, ff. 154-157 (Medina Rioseco, 1704)

5 Las diferencias personales eran enormes. Una gran mayoría de hogares contaban con muy pocas, mientras tapices, doseles, figuras de bulto e imágenes enmarcadas llenaban las salas del resto: como por ejemplo la de Simón de la Cuesta, donde se atesoraban 101 piezas, con una muy frecuente reiteración de advocaciones:

"una pintura de San Pedro Mártir; otra de Nuestra Señora de la Asunción; una de la Magdalena; una de San Juan; un Jesús Nazareno; otra de Nuestra Señora con San Juan; una de la Concepción con San Juan y San Agustín (tasada en 66 rls., era la pieza más valiosa); dos relicarios con vidrieras; un San Francisco de cera con marco y vidriera; once vitelas con marco; cuatro pinturas ordinarias; dos papeles luminados con marcos; ocho papeletas y dos vitelas; una pintura de Nuestra Señora de la Fuencisla; una de Santa Catalina; otra de Nuestra Señora de la Soledad; un dosel con tres láminas y Jesucristo en la cruz; una pintura de Santa Teresa; una de San Antonio; tres de San Francisco; tres pinturas ordinarias de la calle Santiago; una pintura de Nuestra Sefiora del Popolo; dos de Nuestra Señora de la Soledad; una de la Adoración de los Reyes; un San Juan en el desierto; un Cristo atado a la columna; un Cristo en Ja cruz con San Francisco; una Nuestra Señora y San Francisco; un San Onofre; una Santa Clara; dos cuadros ordinarios; un cuadro de El Salvador; otro de San Pablo; otros dos de Nuestra Señora de la Soledad; otro de Santa Isabel; otro de Nuestra Señora de la Piedad; otros dos del Santo Cristo de Burgos; otro de San Diego; otro de Nuestra Seffora de la Cerca; otro de Nuestra Sefiora de la Concepción; otro de San Francisco; otro del arcángel San Miguel; una pintura en tabla blanca; dos vitelas con marcos; un dosel con su pila de latón y cruz de madera; una pintura de San Ignacio; dos de San Francisco; otra de Nuestra Seffora de la Leche; otra de la Magdalena; una con San José, Nuestra Señora y el Niño; otra de San José y Nuestra Seffora; una de San Antonio; una de San Juan y el Niño; otra de Santo Domingo; una de Nuestra Señora del Buen Suceso; otra de Nuestra Seffora de la Soledad; un Nin̄o de Nápoles; un relicario con vidrieras; cuatro vitelas; un cuadro de Santa Catalina; otro de Nuestra Sentora de la Soledad; uno de Cristo y la Magdalena; y, por último, otro del Angel". A.H.P.V., Secc. Prot., Leg. 9444, ff. 541 y ss. (Medina de Rioseco, 1700).

6 Hacia 1700, la mujer de un notario de Medina del Campo repartía varias pinturas entre sobrinas, sobrinos, un niño y un procurador, A.H.P.V., Secc. Prot., Leg. 5433, sin fol..

En Valladolid, la costumbre tampoco era nueva. Ejemplificamos el recordatorio con la manda efectuada por $D^{*}$ Antonia de Simancas, en 1651: a la ermita de Nuestra Señora del Camino cinco 
estos enseres, repartían entre sus familiares y diversas instituciones religiosas y asistenciales buena parte de dichas pertenencias?

I. TESTADORES QUE MANDAN PINTURAS. 1650-1830. Porcentajes.

\begin{tabular}{|c|c|c|c|c|c|c|}
\hline & $\underline{1650}$ & $\underline{1700}$ & $\underline{1750}$ & 1800 & 1830 & TOTAL \\
\hline VALLADOLID & 5,49 & 12,24 & - & 1,34 & 1,12 & 3 , \\
\hline MEDINA RIOSECO & & 12,24 & 21,79 & 14,18 & & 15,82 \\
\hline OTROS PUEBLOS & & 7,24 & 7,84 & 3,84 & & 6,33 \\
\hline TOTAL & 5,49 & 9,05 & 5,15 & 2,80 & 1,12 & 4,66 \\
\hline
\end{tabular}

INVENTARIOS Y PARTICIONES CON PINTURAS

\begin{tabular}{|c|c|c|c|}
\hline & $\underline{1700}$ & $\underline{1750}$ & $\underline{1800}$ \\
\hline MEDINA RIOSECO & $90 \%$ & $85 \%$ & $90 \%$ \\
\hline
\end{tabular}

\section{A. Motivos artísticos. Representaciones sacras.}

La mayoría de las representaciones pictórico-artísticas tenían una temática religiosa $^{8}$. Véanse las tablas II y III.

retablos - Santo Cristo / Nuestra Señora, San José, San Juan y el Niño / Nuestra Señora de la Concepción en Soledad / Nuestra Señora de la Soledad / Nuestra Señora de la Concepción con el Niño en brazos- y "un frontal de mi Oratorio", siendo el otro para el Humilladero del Puente Mayor, al que también tocan distintas prendas de misa y objetos litúrgicos; el convento de los Santos Mártires recibió un cáliz con su patena y una Nuestra Señora de bulto; y una novicia "un cuadro del obispo Pedro de Rojas". Y, por supuesto, se había perdido en 1800, cuando una feligresa dona al oratorio de San Felipe Neri un cuadro de su titular; A.H.P.V., Secc. Prot., Leg. 2936, ff. 23-37.

7 Sus legados en el Valladolid de 1650 a otros miembros del clero eran frecuentes. Un beneficiado vallisoletano, en 1701, mand6 a tres vecinos-as unas pinturas del Santo Cristo de Burgos, de Nuestro Señor difunto, una Nuestra Señora de la Soledad y "una pintura del hermano Jerónimo Benete, persona de ejemplar vida"; A.H.P.V., Secc. Prot., Leg. 2644, sin fol..

El listado podría hacerse interminable: 342 castellanos a lo largo de todo el periodo analizado realizaron alguna manda de este tipo.

8 Únicamente un $5 \%$ correspondia a retratos de antepasados o de miembros de la familia real y varias escenas campestres o paisajísticas; de otro $38 \%$ no podemos asegurar el contenido de la obra: eran "estampas", "láminas", "tarjetas", "vitelas"..., en número abundante, de escaso valor crematístico y de factura desconocida.

Aficiones y devociones en el antiguo régimen Hispania Sacra 50 (1998) 
Nuestra Señora, la Virgen María, o advocada bajo sus múltiples misterios constituyó el tema pictórico más frecuente: de las Angustias y de San Lorenzo, típicamente vallisoletanas, o universalmente reconocida en su Asunción y "Piedad", "del Rosario", "Inmaculada", "de la Soledad", "del Carmen", "de Belén", "de la Leche" o "del Popolo".

Su capacidad de intercesión y mediación con la Divinidad se revalorizó después de Trento: su presencia no podía faltar en las estancias. Doliente o gloriosa, consoladora o inmaculada, en soledad o triunfante, maternal o angustiada, con el Niño o con Cristo muerto en brazos; siempre vigilante, espectante y atenta a sus devotos, recibía miradas y oraciones en cualquier espacio. Sola o rodeada de San José, San Juan o Santa Isabel e imaginada en compañía de Jesús con destacados miembros del santoral, siempre podía alentar a aquellos castellanos, residentes en el campo o la ciudad, tan necesitados de amparo sobrenatural ${ }^{9}$.

La importancia alcanzada por el rosario, los escapularios y las medallas ${ }^{10}$ plasma en objetos apegados al cuerpo la mentalidad de una época. Avemarías, rezos públicos, cofradías del Santo Rosario, concepción inmaculadista e innumerables medallas extendieron y afianzaron la presencia mariana. Lepanto y un edicto de Felipe IV instando a los obispos a la promoción de esta práctica acabaron de enraizarlo en la religiosidad colectiva.

La protección, vigilancia, auxilio e invocación del santoral también era colectiva y popularmente admitida; eso sí, los santos varones superaban en escenificación a las santas. San Francisco, San Antonio, San José, San Juan, San Pedro o San Jerónimo (también, Domingo, Ildefonso, Miguel, Onofre, Santiago y Pedro Regalado) prevalecían sobre Verónica, Magdalena (Catalina y Bárbara) y la santa castellana por excelencia: Teresa de Ávila.

A su lado, Jesucristo, pintado o en efigie, aparecía como el Cristo redentor y salvador del mundo, haciendo competencia al Jesús recién nacido (el Niño Jesús). Los principales momentos de su vida, junto a otros evangélicos, bíbli-

Si las obras son de calidad y tamaño reflejarán un mayor poder económico de los propietarios, pero el espiritu que anima su tenencia y disfrute terrenal y la creencia en la protección sobrenatural de las mismas se incardina no en la cuantificación sino en el recurso asiduo y colectivo a su utilización, no tanto decorativa cuanto de expresión de sentimientos devotos a la búsqueda de su amparo.

9 Como se desprende de las conclusiones vertidas por Jean Delumeau, en sus trabajos: "La Vierge au grand Manteau", conferencia impartida en la École Française de Rome en marzo de 1990; y Rassurer et Protéger. Le sentiment de securité dans l'Occident d'autre fois, Fayard, París, 1989.

10 Para una comprensión general de los "espacios marianos", véase Vida y muerte: la imagina. ción religiosa y Hermandades, Romerías y Santuarios, vols. II y III de La Religiosidad Popular (coords. C. Álvarez Santalo y otros), Barcelona, 1989. Vid. Carlos J. Romero Mensaque, "El fenómeno rosariano como expresión de religiosidad popular en la Sevilla del Barroco", ibidem, vol. Il, pp. 540-553. 
cos y del cristianismo, también alcanzaron un cierto interés decorativo, aunque no tanto como los anteriormente citados.

Aparecía con el Padre y el Espíritu Santo, como Nazareno, Ecce Homo o popularmente conocido por "el Cristo de Burgos"; también Niño o "napolitano". Adorado, huído, orante, cenando al final de sus días, atado a la columna, flagelado, en la cruz (crucificado, rodeado de madre y apóstoles, hablando con los ladrones, abrazado a San Francisco...), descendido, sepultado (casi un $15 \%$ de las obras posían esta temática) como el Salvador, aunque en pocas ocasiones se le representase como resucitado. La importancia simbólica de la cruz se manifestaba a través de una amplia variedad de crucifijos: simples cruces de madera o cartón (colgadas de la pared o al pecho), rodeados de reliquias, "cruces de Caravaca" y ya crucifijos "con el Cristo de bulto", conformaban esta colección devocional.

$\mathrm{Su}$ imagen sola no era suficiente para aquellas mentalidades. La cultura colectiva popular necesitaba de su madre, ángeles guardianes y miembros de su corte celestial, para que se encargasen de vigilar, proteger y ayudar a los pobres mortales que imploraban su auxilio. El santoral, con María a la cabeza, aparecía siempre presente al estar mucho más cerca y conocer mejor las necesidades sociales e íntimas de la población; todos alrededor del Cristo humanizado componían los frecuentes conjuntos redentores decorativos y de referencia sacralizada que diariamente eran visionados nada más levantarse. Muchos ejemplos ilustrativos podrían traerse a colación sobre esta mayor presencia de la Virgen y del santoral, en general religiosa y sacra, vigente en la Castilla del XVIII; baste el de Dominga Macías: su cuerpo de bienes ascendía a 24.274 reales, de los que 359 (un 1,5\%) correspondían a obras artísticas; las 34 piezas se distribuyeron del siguiente modo: VIRGEN, $29,4 \%$, Jesucristo, $14,7 \%$, Conjuntos Redentores, $14,7 \%$, Santos, $11,8 \%$, Santas, $5,9 \%$, Otras, $23,5 \%{ }^{12}$.

"Retratos" y "No Religiosas" solían representar a reyes (sobre todo a Carlos II), emperadores antiguos o a diversos antepasados, reduciéndose su presencia a las familias de cierta alcumia. A su lado aparecían escenas bucólicas, campestres, reposteros, flores, "fruteros", "valencianas", países, cacerías, de la antigüedad y otras de muy diverso contenido ("de los Bobos"), cuyo soporte era el lienzo y el tapiz.

II Vease: Tesoro de Milagros y Oraciones de la Cruz de Caravaca, Buenos Aires, 1981-1987, p. 122; su subtítulo es muy expresivo: "de suma virtud y eficacia para curar toda clase de dolencias, como también un sinnúmero de prácticas para librarse de hechizos y encantamientos con bendiciones y exorcismos, etc.".

12 A.H.P.V., Secc. Prot., Leg. 9188, ff. 496-563 (Medina de Rioseco).

Aficiones y devociones en el antiguo régimen Hispania Sacra 50 (1998) 
II. TiPOLOGÍA DEL ARTE CRISTIANO EN VALLADOLID. 1650-1834. Porcentajes.

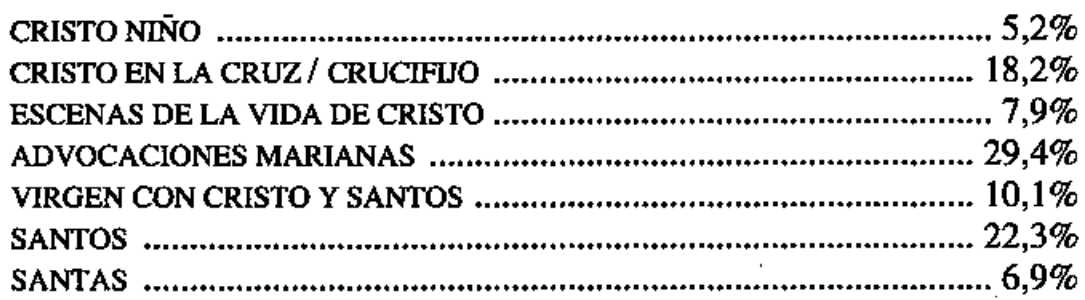

III. REPRESENTACIONES RELIGIOSAS MAS IMPORTANTES. FRECUENCIA REPETTTIVA. VALLADOLID: 1650-1834.

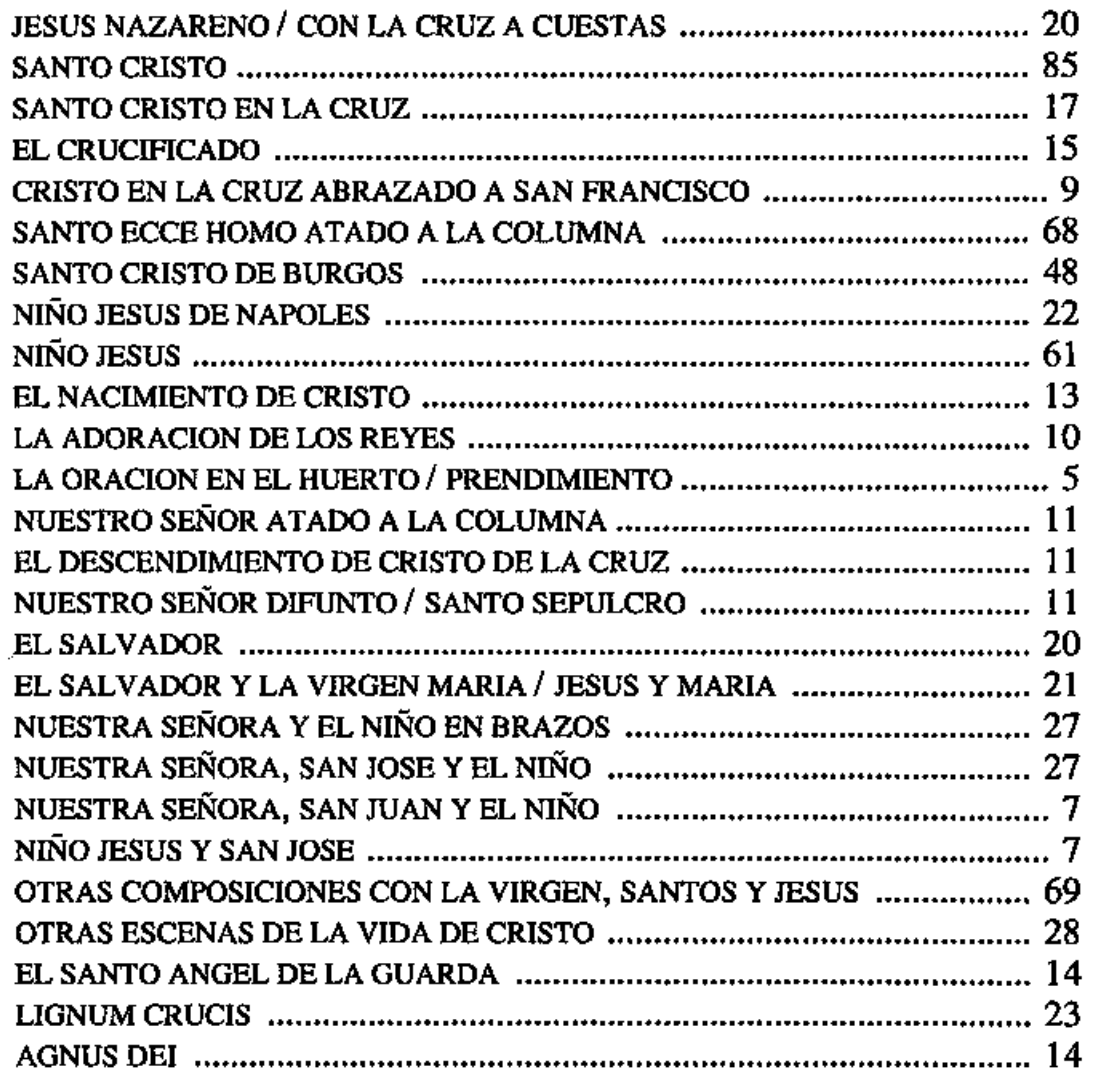




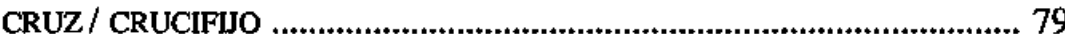
OTRAS ESCENAS EVANGELICAS Y SIMBOLOS DEL CRISTIANSMO ........ 82 CRISTOCENTRICAS (29) ................................. 38,67\% ................... 824

NUESTRA SEN̄ORA LA VIRGEN MARIA …........................................... 101

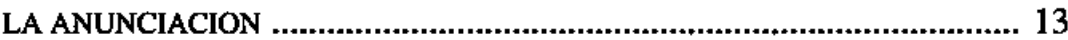

NUESTRA SEÑORA DE LA PIEDAD ..................................................... 13

NUESTRA SEN̄ORA DE LA CERCA …................................................ 5

NUESTRA SEÑORA DEL CAMINO ...................................................... 5

NUESTRA SEÑORA DE LAS ANGUSTIAS .............................................. 14

NUESTRA SEÑORA DE SAN LORENZO .................................................... 9

NUESTRA SEÑORA DEL ROSARIO .................................................... 20

NUESTRA SEN̄ORA DEL SAGRARIO .................................................... 8

NUESTRA SEN̄ORA DE LA CONCEPCION ............................................. 111

NUESTRA SEN̄ORA DE LA SOLEDAD ……........................................... 116

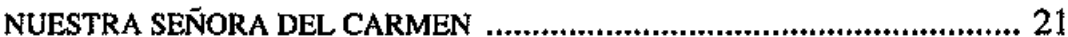

NUESTRA SEÑORA DE LA ASUNCION ................................................ 26

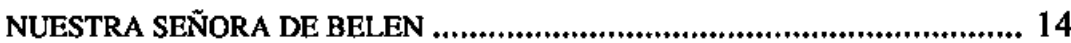

NUESTRA SEÑORA DE LA LECHE ………........................................... 12

NUESTRA SEÑORA DEL POPOLO ..................................................... 34

NUESTRA SEN̄ORA LA VIRGEN MARIA Y DIVERSOS SANTOS ................. 59

OTRAS ADVOCACIONES MARIANAS ..................................................... 105

MARIANAS (18)

SAN AGUSTIN / BAUTISMO DE SAN AGUSTIN ……….............................. 5

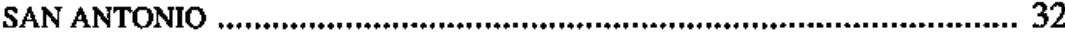

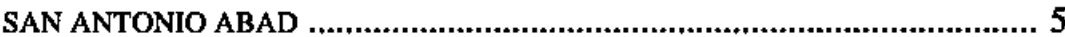

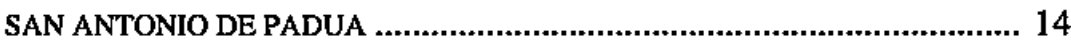

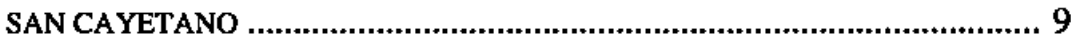

SANTO DOMINGO …………………………………................. 10

SAN FRANCISCO / TRANSITO DE SAN FRANCISCO ……........................ 44

SAN FRANCISCO DE PAULA .......................................................... 10

SAN FRANCISCO JAVIER ................................................................ 5

SAN GREGORIO

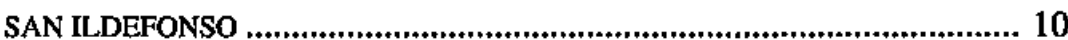

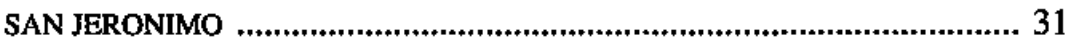

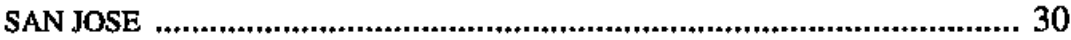

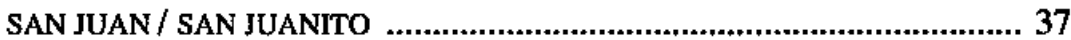

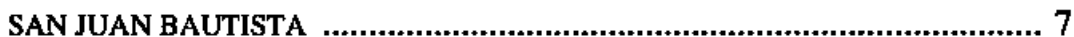

Aficiones y devociones en el antiguo régimen

Hispania Sacra 50 (1998) 


SAN MIGUEL
SAN ONOFRE
SAN PEDRO
SAN PEDRO REGALADO
SANTIAGO
DOCE APOSTOLES / EVANGELISTAS/ DOCTORES
OTROS SANTOS DE LA CORTE CELESTIAL
LA VERONICA
SARTA MAGDALENA BARBARA
SANTA CATALINA
SANTA GERTRUDIS
SANTA ROSA
SANTA TERESA
OTRAS SANTAS DE LA CORTE CELESTIAL
DEL SANTORAL (30)
TOTAL (77)

Otra cosa era la base material de sustento representativo de dicha temática religiosa. La pintura era númerica y cualitativamente la más empleada, y, por tanto, la que mayores variantes y posibilidades iconográficas introducía. En cuadros enmarcados, o sin el soporte del marco, y simplemente como estampas, láminas, tarjetas o vitelas (de reducido tamaño y de bajo precio, por lo que eran más asequibles, contabilizamos a lo largo del periodo analizado: 662 "escenas ordinarias", 177 obras del taller sito en la calle Santiago, 165 láminas, 73 estampas, 179 "países" y hasta 465 vitelas estampadas en piel), las casas castellanas reunían imágenes pintadas por doquier. Primaban las "ordinarias de la calle Santiago" vallisoletana. Se encontraban algunas, eso sí pocas, escenas romanas, napolitanas, florentinas ("a lo florentino"), de Flandes, "valencianas". Esculturas (muchas "tallas de bulto"), tapices y doseles informan de la riqueza mobiliaria de ciertas estancias acomodadas ${ }^{13}$. A su lado, aparecían dípticos, doseles (con el Santo Cristo, la cruz, reliquias, pilas y medallas), "co-

13 Sería otro medio puntual de valoración del "nivel de vida", condiciones de "confort" o de gradación de la pobreza y de posibilidades económico-materiales a través de una documentación ya de por sí, globalmente considerada, băsica para ello. Los primeros muestran unas condiciones de vida superiores a la media, mientras las muy abundantes "estampas y láminas", tarjetas y "escenas ordinarias" la posición contrapuesta. 
razones", "piernas de cera"14, urnas, joyas con la Virgen y Santos, escaparates, retablos, gradas de altar, tabernáculos, frisos....

Todo el conjunto de pequeñas piezas sacras (de orfebrería, latón, madera, papel, etc.) que conformaban cruces, pilas de agua bendita, relicarios, escapularios, medallas y rosarios, tenían amplia cabida en el ajuar típico de los bienes muebles de los castellanos. Como en ninguno de los otros conjuntos artísticos reseñados, el componente devocional, mágico también, de culto y de sentimiento religioso se exteriorizaba a través de plasmaciones culturales de conocimiento y asentimiento público.

La oferta era cuantiosa y su moderado coste satisfacía ampliamente la constante y fuerte demanda. Andrés Morillo, y ni mucho menos era el único vendedor, al comerciar en géneros de cabestrería, contaba con, además de muchas pinturas y objetos sacros: "doce catecismos (a tres reales) y seis libros de Doctrina (6 rls.); doce rosarios de Cachumbo, 12 reales, otras tres docenas de rosarios, 3 rls., dos celemines de lágrimas de rosarios, 12 rls., cuatro cuadros pequeños y uno grande, 36 rls., cinco relicarios pequeños, 30 rls., diez tablas de pinturas, 30 rls., cuatro rosarios, 4 rls., y dos docenas de cruces de Santo Toribio, 8 reales"1s.

Casi todo el mundo poseía unos rosarios, una pila para el agua bendita y algún "relicario de láminas"; otros, en cambio, contaban con una verdadera fortuna en estos objetos ${ }^{16}$. La reliquia se entendía como un continuo medio de contacto físico con lo sobrenatural; el recurso a cruces, medallas, cuentas y retratos de santos, "talismanes milagrosos" e "instrumentos maravillosos y mágicos", también. No extraña, por tanto, los beneficios económicos generados por este comercio sacro tan demandado, ni las redes de distribución construídas en su derredor; tampoco, la búsqueda de "originales", ni el valor conferido al objeto en sí mismo ${ }^{17}$.

Los relicarios también presentaban una importancia singular. No todos contenían una parte corporal o de los bienes tocados por las santas manos de los per-

14 Para comprobar el mantenimiento y arraigo popular de estas prácticas: Mercedes Cano Herrera, "Exvotos y promesas en Castilla y Leơn", La Religiosidad Popular, vol. III, pp. 391-402.

is A.H.P.V., Secc. Prot., Leg. 9446, ff. 98-182 (Medina de Rioseco, 1702).

16 Como Don Antonio de la Cuesta, A.H.P.V., Secc. Prot., Leg. 9222, ff. 411 y ss. (Medina de Rioseco, 1704); o Da Ana María de la Paz, tendera de cerería, A.H.P.V., Secc. Prot., Leg. 2936, sin fol. (Valladolid, 1700).

17 Así, se recuentan 79 crucifijos, 39 pilas de agua bendita, 35 escapularios, 78 medallas, 115 rosarios ("de Jerusalén", con medallas, cruces y láminas de la Virgen) y 425 relicarios ("de monjas"; también con cruces, medallas o estampas de Nuestra Sefiora y Santos).

Vid. Teófanes Egido López, "Religiosidad popular y taumaturgia del barroco (los milagros de la monja de Carrión)", Actas del $/$ Congreso de Historia de Palencia, Palencia, 1990; Tomo III, vol. I, pp. 1 1-39.

Aficiones y devociones en el antiguo regimen

Hispania Sacra 50 (1998) 
sonajes celestiales a que hacían referencia: solían ser imágenes pictóricas de Jesucristo, la Virgen María y los principales miembros destacados del santoral.

\section{B. Marco espacial y cronológico.}

A lo largo del siglo XVIII los cambios no fueron sustanciales.

Las obras más reiteradas (el $26,5 \%$ del total) eran todas de factura religiosa. Pinturas y tallas más abundantes en la capital que en Medina de Rioseco, pero no así en las casas del resto de los pueblos circundantes. Modelos artísticos cuya representatividad iba disminuyendo a medida que el siglo XIX se acercaba (y más acentuado en las zonas rurales), y no debido a la pérdida de importancia de una imagen en particular; el hecho se advierte en todas ellas, cristologicas, marianas o del santoral: la figura del Santo Cristo, el Ecce Homo, el Santo Cristo de Burgos, Nuestra Señora la Virgen María, la Inmaculada Concepción y Nuestra Señora de la Soledad fueron perdiendo relevancia muy lentamente.

A pesar de todo, eran y seguirían siendo durante mucho tiempo las de mayor demanda y presencia popular: las imágenes de la Soledad y la Inmaculada estaban presentes siempre en todas las casas, tanto a mediados del siglo XVII como en la década de los años treinta del XIX.

El contraste urbano-rural en este aspecto es mínimo. Mayor presencia de Cristo, escenas evangélicas y, sobre todo, "no religiosas" en Valladolid"18, frente a más rosarios, relicarios y medallas en la rural, además de sus abundantísimas láminas y pinturas ordinarias, de peor calidad, exponentes de un nivel medio de poder adquisitivo menor. La Virgen y todo el santoral aparecía en ambos entornos a la cabecera del mundo escatológico colectivo. Lógicamente, marcándose las preferencias locales: en Portillo, San Jerónimo; en Medina de Rioseco, la Magdalena, Nuestra Señora de la Piedad y del Rosario y Santiago; en Valladolid, Nuestra Señora de San Lorenzo... pues cada advocación, por motivos diversos, iba imponiéndose universalmente o "ganando y acotando sus propios territorios": Nuestra Señora de Soterraña en Olmedo y toda Segovia; la del Henar, por la zona de pinares....

Los objetos milagrosos no eran, ni nucho menos, exclusivos del mundo rural ${ }^{19}$. Muchos vallisoletanos de la capital contaban con múltiples relicarios,

18 Podemos traer aquí a colación el amplio y valioso patrimonio artístico del escribano del Número de Valladolid Don José Martín de Villa, A.H.P.V., Secc. Prot., Leg. 2937, sin fol. (1702).

39 Las reliquias, como 'fuentes de seguridad', ligaban, en un contacto directo, a los fieles con el más allá. En el XVII se formaron las principales "colecciones" de reliquias y tuvo lugar el auge de los Relicarios. Durante el XVIII 'la pasión se serena'; no pierden su importancia y su culto busca la autenticidad (gran problema teológico y cultual, hasta llegarse a exigir el 'curriculum de las reliquias' 
'estampillas, escapularios y demás joyas sacralizadas. Baste un ejemplo. Antonio Arias era un vecino de la parroquia de El Salvador, allá por 1701. Cuadros, pinturas, países y láminas, decoraban sus aposentos; rosarios, relicarios y un Lignum Crucis, también. Entre sus piezas más preciadas aparecían: "una uña de la gran bestia engarzada; una cadena de alquimia; y siete cuentas para el dolor de muelas" 20 .

La evolución cronológica tampoco fue grande (aún no era el tiempo fuerte de apogeo de los Sagrados Corazones de Jesús y María o de la Sagrada Familia). Los temas heredados se reiteraban sistemáticamente ${ }^{21}$, aunque todos iban sufriendo la misma merma porcentual hacia finales del siglo XVIII; la razón estribaba en el fuerte incremento de las obras "sin especificar". La "permanencia" de los campos temáticos primaba sobre la evolución.

\section{LA ONOMÁSTICA: LA ANTROPONIMIA.}

El 'nombre' en España no ha sido suficientemente estudiado en su dimensión histórica. Es imprescindible atender este capítulo para alumbrar parte de la mentalidad de una época ${ }^{22}$.

El nombre, el apellido y el don tenían una gran importancia durante el Antiguo Régimen, pero no en la misma medida que en fechas contemporáneas. El nombre reflejará, junto a una identidad personal, la fuerza transmisora de las costumbres tradicionales y los lazos familiares que las sustentaban, cuando no y paralelamente la mentalidad de un periodo histórico. El nombre del padremadre y de los padrinos, el/los santos del día inscritos en el calendario, otros santos de devoción particular, la cultura mariana imperante, la advocación parroquial o de ciertas imágenes y santuarios cercanos, las preferencias del

para permitir su culto), más que las cantidades ingentes; véase, Domingo González Lopo, "El papel de las reliquias en las prácticas religiosas de los siglos XVII y XVIII", Mensalidad e Ideología en el Antiguo Régimen, 一vol. II--, Murcia, 1993, pp. 247-260.

${ }^{20}$ A.H.P.V., Secc. Prot, Leg. 3016, ff. 14-27 (Valladolid).

21 La imagen fue siempre el mejor vehículo de adoctrinamiento popular. No obstante y paradógicamente, en Cádiz, el consumo artístico evolucionó desde un predominio de la temática 'profana' en la centuria decimosexta hacia la consagración abrumadora de la religiosa (hagiograficas y marianas), tras descender la anterior, durante el siglo XVIII; véase, A. Morgado, "El consumo artístico en el Cádiz de los siglos XVII y XVIII", Mentalidad e Ideología en el Antiguo Régimen, --vol. II-, Murcia, 1993, pp. 339-349.

22 Mientras, en Europa esta laguna histórica va siendo subsanada. Véase: C. Ginzburg y C. Ponti, "Il nome e il cognome: scambio ineguale e mercato historiografico", Quaderni Storici, 1979, n" 40, pp. 181-190; o las obras colectivas: Leonard, Marie, Jean et les autres. Les prénoms en Limousin depuis un millénaire, CNRS., París, 1984, p. 229; y Le Prénom, Mode et Histoire, Actas del Entretiens de Malher, París, 1980, p. 398.

Aficiones y devociones en el antiguo régimen Hispania Sacra 50 (1998) 
cura, el patrono local y gremial, el ser expósito... marcaron el futuro apelativo del bautizado hasta su muerte (siempre que un mote no lo sustituyese), como fiel reflejo de sociedad sacralizada y patriarcal.

Podían no saber ni escribir sus nombres, pero al sonido de María, Francisco, Manuel, José, Juan o Pedro - y sus variantes femeninas-- reconocían su antropónimo.

El seguimiento de la onomástica permite rastrear la importancia de las devociones del santoral, su popularidad y la extensión de su culto, así como su evolución histórica. La frecuencia de su aparición individualizada o en agrupamientos nominales nos introducirá en el mundo de las mentalidades populares: ideologización marcada desde púlpitos y pilas, pero también desde las ermitas marianas de fuerte impronta local y tradicional. La elección del nombre del niño muestra la monótona permanencia del sentido devocional de predilección registrado por padres y padrinos hacia ciertos santos, advocaciones marianas o invocaciones y "misterios" religiosos. Un texto de la época explica las causas de costumbre tan reiterada: turas?

- ¿Por qué esta costumbre de poner siempre nombres de santos y santas a las cria-

- Buena pregunta.... Y ésto por tres razones:

La primera, para hacerle aquella especial honra y obsequio a aquel santo cuyo nombre se pone a la criatura, y con esto empeñado a que la coja debajo de su protección y la ampare siempre, de modo que no se le ha de poner al niño Andrés porque su padre se llame Andrés, ni Pedro porque su abuelo se llamó Pedro.

La segunda de ponernos nombres de los santos es para que con nuestra devocion les procuremos pagar su patrocinio.

Pero muy principalmente los favorecen cuando ellos los siguen con la imitacion de sus virtudes. Esta es la principalísima razón de ponerse el nombre de los santos y santas ${ }^{23}$.

A la vez que se honraba al titular advocado, se confiaba en su patrocinio y protección. No es menos cierto que el peso familiar era tan fuerte que determinaba muchas de las nominaciones, pero el arraigo ideológico del poder en la tierra de lo sobrenatural determinaba el nombre de muchos de los bautizados. La consecuencia directa fundamental fue la reiterada monotonía antroponímica que trasluce la sociedad sacralizada castellana.

23 Juan Martínez de la Parra, Luz de verdades catolicas y explicación de la doctrina christiana..., Barcelona, 1700, pp. 5-6. 
EL RECURSO AL SANTORAL EN CASTILLA, DEL BARROCO A LA ILUSTRACIÓN... 149

IV. EL NOMENCLATOR CASTELLANO. 1650-1834.

TOTAL HOMBRES MUJERES

\begin{tabular}{|c|c|c|c|}
\hline ... & $16,9 \%$ & $13,6 \%$ & $3,3 \%$ \\
\hline FUNDADORES ORDENES RELIGIOSAS...... & $19,7 \%$ & $12,1 \%$ & $7,6 \%$ \\
\hline 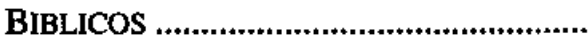 & $36,6 \%$ & $13,5 \%$ & $23,1 \%$ \\
\hline$\ldots$ & $11,2 \%$ & $4,8 \%$ & $6,4 \%$ \\
\hline ELIGIOSA ….................... & $2 \%$ & $0,7 \%$ & $\%$ \\
\hline 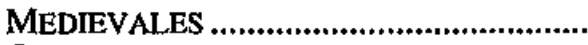 & $5,2 \%$ & $3,5 \%$ & $1,7 \%$ \\
\hline .. & $8,5 \%$ & $3,4 \%$ & \\
\hline
\end{tabular}

V. ANÁLISIS DE LOS PRINCIPALES NOMBRES. 1650-1834. Procentajes.

$\begin{array}{lrlrlr}\text { HOMBRES } & \% \% & \text { MUJERES } & \% \% & \text { TOTAL } & \% \% \\ \text { ALONSO } & 2,3 & \text { ANA } & 5 & & \\ \text { ANDRES } & 2,8 & \text { ANGELA } & 2 & & \\ \text { ANTONIO } & 5,5 & \text { ANTONIA } & 3,5 & \text { ANTONIO-A } & 4,5 \\ \text { FRANCISCO } & 9,8 & \text { FRANCISCA } & 4,2 & \text { FRANCISCO-A } & 7,1 \\ \text { JOSE } & 7,6 & \text { JOSEFA } & 4,8 & \text { JOSE-FA } & 6,2 \\ \text { JUAN } & 8,4 & \text { JUANA } & 3,4 & \text { JUAN-A } & 5,9 \\ \text { MANUEL } & 9,9 & \text { MANUELA } & 4,8 & \text { MANUEL-A } & 7,4 \\ \text { MIGUEL } & 2,0 & \text { CATALINA } & 4,4 & & \\ \text { PEDRO } & \mathbf{6 , 2} & \text { ISABEL } & 6,1 & \text { PEDRO-PETRA } & 3,6 \\ \text { SANTIAGO } & 1,8 & \text { MARIA } & 22,6 & \text { MARIA-NO } & \mathbf{1 1 , 1} \\ \text { TOMAS } & 1,9 & \text { TERESA } & 3,2 & & \\ \text { TOTAL } & \mathbf{5 8 , 3} & \text { TOTAL } & \mathbf{6 3 , 7} & \text { TOTAL } & \mathbf{4 6 , 6}\end{array}$

Fuente: VVAA., Leonard, Marie, Jean et les autres. ob. cit. En esta obra tambien destacan aspectos como: "Nacimiento y desarrollo de un modelo" (pp. 21-117); "Los nombres de la familia de Cristo (s. XVI-XVII)" (pp. 71-75); "La anatomía del modelo" (pp. 76-85); "La transmisión familiar (pp. 92-105); y "La lenta degradación del modelo" (pp. 119-172).

Completando esta nómina, la evolución de los nombres en Fronton (fuente: VVAA., Le Prénom..., ob. cit.. (Artículo de J-F. Delord, p. 94), fue la siguiente:

$\begin{array}{llrrr} & \underline{\mathbf{S} . \mathrm{XVI}} & \underline{1620-659} & \underline{1720-759} & \underline{1820-839} \\ \text { JEAN } & 22,35 & 37,09 & 24,39 & 24,19 \\ \text { PIERRE } & 12,15 & 14,70 & 16,91 & 18,05 \\ \text { ANTOINE } & 11,37 & 9,58 & 8,15 & 8,69 \\ \text { JEANNE } & & 24,59 & 18,20 & 19,23 \\ \text { ANTOINETTE } & & 9,91 & 9,16 & 6,93 \\ \text { MARGUERITE } & & 8,78 & 8,32 & 7,10 \\ \text { MARIE } & & 7,31 & 13,98 & 20,97\end{array}$

Aficiones y devociones en el antiguo régimen Hispania Sacra 50 (1998) 


$\begin{array}{llll}\text { HOMBRES } & \% \% & \text { MUJERES } & \% \% \\ \text { AGUSTÍN } & 1,3 & \text { AGUSTINA } & 1 \\ \text { BARTOLOME } & 0,8 & \text { AGUEDA } & 0,8 \\ \text { BERNARDO } & 1,1 & \text { ANA MARIA } & 1,2 \\ \text { DIEGO } & 1,5 & \text { BEATRIZ } & 0,9 \\ \text { DOMINGO } & 1,5 & \text { BERNARDA } & 0,9 \\ \text { FELIPE } & 1 & \text { FELIPA } & 0,8 \\ \text { FERNANDO } & 0,9 & \text { LUCIA } & 0,9 \\ \text { GABRIEL } & 1 & \text { INES } & 1,5 \\ \text { GASPAR } & 0,7 & \text { JULIANA } & 0,9 \\ \text { GREGORIO } & 1,1 & \text { MAGDALENA } & 0,8 \\ \text { JERONIMO } & 1 & \text { JERONIMA } & 0,8 \\ \text { JOAQUIN } & 0,7 & \text { MARGARITA } & 0,8 \\ \text { JUAN ANTONIO } & 0,6 & \text { M. }{ }^{2} \text { ANTONIA } & 0,6 \\ \text { LORENZO } & 0,9 & \text { M CRUZ } & 0,6 \\ \text { LUIS } & 1,1 & \text { PETRA } & 0,8 \\ \text { MARCOS } & 0,7 & \text { ROSA } & 0,8 \\ \text { MARTIN } & 0,7 & \text { TOMASA } & 1,1 \\ \text { MATIAS } & 0,7 & & \\ \text { SEBASTIAN } & 0,9 & & \\ \text { SIMON } & 0,8 & & \\ \text { VICENTE } & 0,9 & & \end{array}$

El apostolado (con la excepción explicable de Judas) cubría buena parte de las necesidades de protección nominal de varones y mujeres. Juan-a $(6 \%$ del nomenclator) aunaba la devoción al apóstol (cercano a la pasión de Jesús) y al bautista: reuniendo grandes privilegios de salvación. La mención de PedroPetra suponía una absoluta relación con las llaves del cielo y con el franqueo airoso de las puertas del paraíso. Qué decir de los Andreses, Tomases y del santo patrón de España.

Tampoco podía faltar el interés por los fundadores de las órdenes religiosas: Francisco (el más corriente entre los hombres tras Manuel, con un 10\%), Antonio,... y Teresa. Desde sus canonizaciones, y más donde uno de sus monasterios eclipsaba al resto, era frecuente y asidua su nominación junto a las pilas bautismales. Avila y amplias zonas rurales castellanas no podían sustraerse al atractivo teresiano, con una representación mucho más numerosa que en el resto de Castilla y Aragón.

Aficiones y devociones en el antiguo regimen

Hispania Sacra 50 (1998) 
Miguel era el principal guerrero celestial. Su lucha fue un símbolo a la cabecera del moribundo. Angel-a, Gabriel-a y Rafael-a contaban con el mismo papel guardián y custodio.

A su vez, la resistencia al cambio antroponímico provocaba que nombres medievales o paleocristianos persistiesen con fuerte raigambre, como Alonso o Catalina.

Cristo y sus más cercanos eran indispensables en el nomenclator castellano. Jesús será nombre del XIX, pero Manuel-a era el más utilizado por hombres y mujeres, tras el vacío medieval (igual que José). Mientras la referencia a Santa Ana perdía terreno, Santa Isabel aparecía bien representada; y, sobre todo, sus padres: María y José.

Si once nombres cubrían el 64\% del elenco antroponímico femenino, s6́lo María, o su nombre compuesto, designaba ya a más de una quinta parte. Su afianzamiento barroco reafirmaba el catolicismo militante frente a la reforma, y el poder de los santuarios marianos de la zona. Su reiteración provocaba su hegemónico soniquete y el sentido popular mariano.

José-fa alcanzó su eclosión en el barroco. Las razones de su popularidad y divulgación masiva procedía de los numerosos sermones que exaltaban su figura -de inspiración teresiana--, la universalización de su festividad durante el siglo XVII y su amparo efectivo desde la cuna hasta la sepultura: protector de expósitos y siempre abogado de una buena muerte ${ }^{26}$.

La evolución de estos escasos aunque primordiales nombres fue significativa. La mayoría presentaron una fuerte estabilidad a lo largo del Antiguo Régimen, fruto de su arraigo cultural. Varios perdieron posiciones, en mayor o menor medida, tanto bíblicos como paleocristianos o medievales. Entre otros: Pedro-Petra, Andrés, Alonso, Domingo, y, sobre todo, los vocablos femeninos Ana (sin tener en cuenta a las muchas Ana María), Isabel, Catalina e Inés. Su apogeo visigotico-medieval se eclipsó, siendo relevados; mientras Diego desciende, Santiago se estabilizó e incluso alcanzaba sus máximos a comienzos del siglo XIX.

Francisco-a y Juan-a, a pesar de su frecuente uso, fueron retrocediendo. No ocurrió así con los otros dos antropónimos más demandados: José-fa y Ma-

$26 \quad 1596-1600 \ldots \ldots \ldots . . . . .0,8 \%$ de Josés sobre el total de vallisoletanos.

$1646-1650 \ldots \ldots . . . . . . .5,8 \%$.

$1696-1700 \ldots . . . . . .12,2 \%$.

Vid. Teofanes Egido López, "San José y la antroponinia de Valladolid", Presencia de San José en el siglo XVII, Actas del Cuarto Simposio Internacional Josefino y Estudios Josefinos, 41 (1987), pp. 512-514.

Para comparar estos datos con los de las dícesis colindantes, véase: T. Egido y L. Rodríguez Martínez, "La devoción popular a San José en el Antiguo Régimen", Estudios Josefinos, 38 (1984), pp. 225-249. 
nuel-a ascendieron durante la segunda mitad del Setecientos, tras su asentamiento definitivo en la centuria precedente.

Vicente, Tomás-a o Rosa presentaron su punto álgido hacia 1800. Y aunque su fuerza fuese anterior, también Teresa (debido a su fama y presencia en el mundo rural) y Miguel eran más nombrados en las pilas bautismales por esas mismas fechas.

El nombre de María constituye un caso especial. Por supuesto, era el apelativo más frecuente en cualquier periodo histórico, pero perdiendo posiciones respecto a Josefas o Antonias; sin embargo, su destronamiento no fue tal, debido al progresivo incremento de todos aquellos nombres compuestos con el topónomo María más otro nominal posterior o precediéndole: Ana MaríaMaría Ana, María Antonia, María del Carmen, María Concepción, María Cruz, María Francisca, María Ignacia, María Josefa, María Manuela o María Teresa.

\section{B. Contraste espacial y cronológico de la tipología nominal.}

El Antiguo y Nuevo Testamento ofrecían una fuente inacabable de posibles nombres para los castellanos de los siglos XVII, XVIII y aún del XIX. Cerca del $57 \%$ de los vallisoletanos contaron con una seña de identidad proveniente de dicho origen religioso. Pero es que otro tercio del nomenclator se debía a la fama y reputación de los distintos fundadores más o menos tardíos de las órdenes religiosas más representativas e implantadas en la región ( $y$ todo el orbe cristiano), eran paleocristianos - primeros mártires y padres de la Iglesia llevados a los altares por su vida ejemplar- o de una clara simbología religiosa. Siempre surgirá el problema de encuadrar a los numerosos Franciscos o Domingos.

El escaso resto tenían un origen visigótico-medieval y grecolatino, $o$ adquirieron una nueva o mayor pujanza desde finales de la centuria decimoctava. Mientras unos descendían porcentualmente su representación, "nuevos" antropónimos iban incorporándose al vocabulario habitual; así, entre otros, hemos constatado como aparecidos por vez primera hacia 1800 a: Natalio, Ángelo, Engracia, Fabiana, Felisa, Buenaventura, Alejandra, Eulogio, Demetrio o Judas. PabloPaula, Ignacio y Francisco Javier también eclosionaron en esos momentos ${ }^{27}$.

27 Nombres que ś6lo aparecen una vez: MAScuLıNOs: Amaro, Apolo, Asensio, Atilano, Celedón, Etacio, Fulgencio, Guillermo, Íñigo, Jaime, Lesmes, Patricio, Prudencio, Roberto, Severino, Simeón, Teodosio, Valerio y Velasco. Unicamente en el siglo XIX: Abdón, Acisclo, Antero, Atanasio, Augusto, Baudilio, Braulio, Calixto, Casiano, Casimiro, Cecilio, Celedonio, Ciriaco, Eleuterio, Estanisłao, Faustino, Froilán, Fructuoso, Gerardo, Ginés, Gumersindo, Hermógenes, Higinio, Hilario, Indalecio, Jorge, Julián Eladio, Justo, Marceliano, Mauro, Nemesio, Pantaleón, Paulino, Plácido, Policarpo, Robustiano, Rodolfo, Román, Romualdo, Rosendo, Rufino, Ruperto, Sandalio, Segundo, Sergio, Severiano, Silverio, Simplicio, Tadeo, Telesforo, Teodoro y Venancio.

Aficiones y devociones en el antiguo régimen Hispania Sacra 50 (1998) 
VI. REITERACIÓN DE NOMBRES PROPIOS. Valladolid: 1650-1834. Procentajes.

\begin{tabular}{|c|c|c|c|c|c|c|c|}
\hline & $\underline{1650}$ & $\underline{1700}$ & $\underline{1750}$ & $\underline{1800}$ & $\underline{1830}$ & VALLADOLID & PUEBLOS \\
\hline ALONSO & 2,5 & 4,6 & 2,1 & 1,2 & 0,4 & 1,7 & 3,3 \\
\hline ANDRES & 3 & 3,5 & 3,9 & 1,7 & 1,5 & 2,1 & 3,8 \\
\hline ANTONIO & 5,7 & 6,9 & 5,6 & 5,3 & 3,4 & 4,9 & 6,3 \\
\hline FRANCISCO & 11,2 & 12,6 & 9,2 & 7,1 & 7,9 & 9,6 & 10,2 \\
\hline JOSE & 7,6 & 5,4 & 10,6 & 8,2 & 6,7 & 7,5 & 7,8 \\
\hline JUAN & 9,6 & 12,9 & 7,2 & 5 & 5,7 & 8,5 & 8,2 \\
\hline MANUEL & 8 & 7 & 13,2 & 14,6 & 7,6 & 8,8 & 11,6 \\
\hline PEDRO & 9,5 & 6,7 & 5,1 & 3,9 & 5,4 & 7,4 & 4,5 \\
\hline ANA & 3,9 & 9,8 & 6 & 3,2 & 0,9 & 3,5 & 7,5 \\
\hline ANTONIA & 3,2 & 4,4 & 2,8 & 4,9 & 2,2 & 3,2 & 4 \\
\hline CATALINA & 4,7 & 7 & 4,6 & 3 & 1,3 & 3,5 & 5,8 \\
\hline FRANCISCA & 4 & 5,1 & 4,5 & 4 & 3,2 & 3,8 & 4,9 \\
\hline ISABEL & 5,2 & 10,3 & 7,9 & 4,2 & 1,9 & 4,5 & 8,8 \\
\hline JOSEFA & 3,5 & 3 & 7,3 & 6,2 & 4,9 & 4,3 & 5,6 \\
\hline JUANA & 4,8 & 2,9 & 1,8 & 2,9 & 3,9 & 4,3 & 1,8 \\
\hline MANUELA & 3,2 & 4,4 & 6,9 & 6,4 & 3,7 & 3,9 & 6,1 \\
\hline MARIA & 11,6 & 23,4 & 18,2 & 15,8 & 13,8 & 14,2 & 20,3 \\
\hline
\end{tabular}

Los de referencia bíblica eran abrumadoramente mayoritarios, destacando la importancia de los nombres marianos; también, los provenientes del apostolado concitaban entre los varones un uso asiduo. Marías, Manueles-as, JosésJosefas, seguidos de Migueles, Anas e Isabeles, provocaron que entre las féminas fuese difícil diferenciar a unas de otras simplemente por su nombre de pila. En cambio, los hombres se valieron del apostolado al elegir nombre: Juan (también muchas Juanas), Pedro y Andrés estaban a la cabecera del elenco preferencial. También eran interesantes las concentraciones nominativas en torno a los Reyes Magos, la trilogía de arcángeles y Lázaro-Marta - a veces unidos a Magdalena-.

En el mundo medieval, hombres fueron también los principales organizadores de nuevas reglas. Los de Asís y Pađua nunca fueron olvidados, situándose

FEMENINOS: Acacia, Alberta, Aldara, Aleja, Antonina, Aureliana, Bibiana, Braulia, Bruna, Cándida, Casimira, Carlota, Celestina, Cipriana, Ciriaca, Columba, Constanza, Críspula, Ebarista, Emeteria, Estefanía, Fausta, Floriana, Fermina, Gabina, Gala, Gila, Justa, Leandra, Leocadia, Leona, Luciana, Mauricia, Nemesia, Nicasia, Pantaleona, Petronila Manuela, Potenciana, Rosalía, Ruperta, Salustiana, Saturnina, Serapia, Sofia, Susana, Trifona, Urbana, Valeria, Valeriana y Vicencia. Ś́lo en el siglo XIX: Casta, Flora, Geroma, Ginesa, Matía, Matilde, Pinfina y Raimunda. 
entre los de más frecuente advocación en todas las épocas. Agustinos, dominicos, diegos y jerónimos se disputaban continuamente un hueco en la pugna regular por extender su influencia y presencia activa en la sociedad; el influjo y poderío de la orden jesuita calaría algo posteriormente. En Valladolid, franciscas, brígidas y claras, mas las omnipresentes teresianas, terminaban de conformar las escasamente variadas posibilidades de elección femeninas.

Por el contrario, Alonso, Luis-a, Fernando, Beatriz, Carlos y Ramón perduraron, con un vigor claramente descendente - tras la baja "ilustrada" volvió su "moda" durante el romanticismo--, en la semiinmóvil antroponimia masculina española del Antiguo Régimen.

Nombres con un origen más antiguo aún en la cultura mediterránea: Catalina, sobre todo, Gregorio, Lorenzo, Sebastián, Vicente, Inés, Lucía, Martín, Agueda y Margarita, vírgenes y mártires del santoral cristiano, continuaron superando el $10 \%$ del elenco nominal, como expresión clara de la inercia de los nombres y del peso de las estructuras eclesiásticas.

Los todavía escasos nombres de una fuerte simbología religiosa -misterios y advocaciones cristológicas o marianas-, sólo desde comienzos del siglo XIX comenzaron a tener plena vigencia. El ángel custodio, el día de todos los Santos, "Víctor-Victoria", "Gracia", Cristina, el misterio Pascual, la natividad y epifanía de Cristo o los Dolores de Nuestra Señora y la Virgen del Carmen formaron parte de aquel nuevo vocabulario.

Dentro de la escasa variedad reinante, ésta era sensiblemente superior en la capital, debido a la abrumadora presencia de "María" (23\%) en el ámbito rural.

Resumiendo las diferencias entre Valladolid y su zona rural circundante, en cuanto a las referencias al apostolado, sólo Andrés y, en segundo plano, Matías primaron en los pueblos (frente al Pedro urbano). Había nombres netamente "urbanos", como: Ángela, Felipa, Juana, Juliana, Margarita, Petra o Tomasa; mientras, Beatriz, Bernarda, Catalina, Francisca y, sobre todo, Ana, Isabel, Josefa, Manuela y Teresa serían más "rurales". Lo mismo ocurría entre los varones: en el mismo orden anterior Pedro, Domingo o Luis, frente a Francisco, Bernardo, Agustín, Jerónimo, Matías o Alonso, Andrés, Antonio y Manuel. En el caso de María no hubo competencia entre ambos ámbitos; Francisco predominaba en Valladolid $(9,6 \%)$ y Manuel al salir de las puertas de la ciudad $(11,6 \%)$ hasta convertirse en el más difundido.

En cuanto a la evolución secular, debe destacarse, en primer lugar, su fuerte resistencia al cambio (José no era una excepción). Implantados, inmovilismo, monotonía y dificultades para la transformación modernizadora definieron su dinámica evolutiva. Así, no fue hasta bien entrado el siglo XIX-XX cuando empezó a percibirse que no todos se llamaban de la misma manera. Afianzado el

Aficiones y devociones en el antiguo régimen Hispania Sacra 50 (1998) 
proceso sacralizador, desde mediados del Setecientos José fue casi tan nombrado como María o Manuel, hasta disputar y arrebatar el protagonismo a Francisco.

Mientras José se estabilizaba al alza, Josefa experimentó un fortísimo desarrollo i en la misma línea que el presentado por Teresas, Rosas o Agustinas, y sin olvidar el repunte tardío de Felipa, Juana, Juliana, Margarita y Tomasa. El omnipresente nombre de María tendió a descender desde el elevado 23,5\% de 1700. Pero no es menos cierto que aumentaron espectacularmente los compuestos que contenían en primer o segundo término dicho vocablo, entre los que destacaban María Antonia, María Concepción, María Cruz, María Josefa o María Manuela y las indisolubles desde 1800: Ana María, María del Carmen y María Teresa.

Los nombres compuestos empezaron siendo un claro signo de distinción social, para convertirse en otro de los símbolos de reafirmación mariana y de mixtura protectora de los principales nombres del santoral. Así, hasta el siglo XIX la mayoría de los bautizados recibían un sólo nombre; el mínimo resto se componía de varios vocablos, en un amplio porcentaje sólo dobles. Siempre escasos, su presencia fue aumentando progresivamente: $2,9 \%$ en $1700,6,5 \%$ (1750), en 1800 otro $6,4 \%$ y hacia 1834 alcanzaban ya un $7,9 \%$. Francisco Javier iniciaba un listado (pleno de sentido de abogacía) que se continuaba con Ana Isabel, Ana..., Juan Antonio, Juan Bautista, Juan Manuel, Juan... y todos los compuestos con María.

\section{IMPORTANCIA RELIGIOSA DEL ENCABEZAMIENTO TESTAMENTARIO: LAS CLÁUSULAS RELIGIOSAS.}

El testamento era un acto de pleno significado religioso y otro de los medios recomendados para bien morir. Su encabezamiento era un claro símbolo de invocación supraterrenal, bajo el cual se encuadraba todo el formulismo de las distintas cláusulas. El realizar profesión de fe y la aceptación de esas verdades constituía un acto colectivo de uniformidad dogmática y de uniformización social, a la vez que una expresión devocional personal. La variedad de intercesores era mínima, pero cuando señalaban "todos los santos de la corte celestial" ¿qué más podían demandar?. La encomendación presentaba el mismo significado.

La versatilidad de este encabezamiento era prácticamente nula, y el esquema básico, el contenido y las expresiones solian repetirse continuamente. Esa misma uniformidad confiere al testamento su carácter eminentemente religioso y describe el ambiente impregnado de lo sacro existente en Castilla durante la 
Edad Moderna ${ }^{28}$. Se produjo un aumento de la expresividad de las fórmulas, un incremento de la variedad de las mismas y un uso creciente de expresiones únicas; a la vez que una pérdida de barroquismo, en la tendencia hacia la sencillez presente en el siglo XVIII frente a concepciones culturales precedentes: "el discurso se hace, pues, más extenso y más complejo, así como más individualizado"29.

Estamos de acuerdo con la clasificación de testamentos formulada por $\mathrm{Ph}$. Ariès. Establece una división cuatripartita de las declaraciones de últimas voluntades, de la que descartando la última (en la que "toda alusión de naturaleza religiosa ha desaparecido", que dice no ser rara a finales del siglo XVIII, haciéndose cada vez más frecuente a principios del XIX) por inexistente en nuestra muestra, nos centramos en las tres (más bien dos) restantes. La primera sigue el modelo tradicional de los siglos XVI-XVII, donde el preámbulo religioso es amplio y extenso (como variedad de ésta surge el "modelo simplificado"). La categoría más numerosa en la segunda mitad del XVIII se compondría de las disposiciones en las que no se otorga ninguna instrucción particular y todo se remitiría a la voluntad expresa de los herederos. Domina el sentimiento de confianza familiar y el de voluntad de sencillez al no entrar en detalles y, en cierta manera, despreocuparse de las pompas mortuorias ${ }^{30}$.

Valladolid no es un caso aislado. Su área rural circundante, Cádiz y Oviedo ofrecen porcentajes del $100 \%$, incluso ascendiendo desde el $97,7 \%$ de principios de siglo: no se concibe un testamento sin esta primera llamada sacra ${ }^{31}$. En cuanto a la Profesión de Fe, en Oviedo y Cádiz se constata un incremento de la

28 Domingo González Lopo, "La actitud ante la muente en la Galicia Occidental en los siglos XVII y XVIII", /I Coloquio de Metodología Histórica Aplicada, Santiago de Compostela, 1984, pp. 125-138. Resume las invocaciones preambulares, admitiendo procentajes superiores al $81 \%$ de "testamentos perfectos".

Para apreciar el acatamiento a la doctrina eclesiástica de las cláusulas religiosas testamentarias, véase las Constituciones Sinodales Vallisoletanas (Valladolid, 1606), "De Summa Trinitate et Fide Catholica", Tít. I, Lib. I, pp. 1-65.

$29 \mathrm{M}^{2}$ José de la Pascua Sánchez, Actitudes ante la muerte en el Cádiz de la primera mitad del siglo XVII, Cádiz, 1984; p. 93.

$30 \mathrm{Ph}$. Ariès, El hombre ante la muerte, Madrid, $1983 ;$ p. 390.

La documentación testamentaria ofrece una mayoría del tipo 'simplificado', al que acompañan, interconectados, los del tercer gnupo. La asociación entre voluntad de sencillez de los funerales y la decisión de remitirse al ejecutor testamentario, sin mermar el mantenimiento universal de las cláusulas testamentarias preliminares, es la constante más habitual. El sustrato religioso persiste, incluso afianzado, y a él se agrega la humildad predicada por el catolicismo, fundiéndose en un todo sacralizado.

31 Roberto J. López, Oviedo: muerte y religiosidad en el siglo XVII. Un estudio de mentalidades colectivas, Oviedo, 1985; p. 54.

En Cádiz, el calificativo "Todopoderoso" parece utilizarse con mayor asiduidad $(51,24 \%)$ en 1750; mientras que en Oviedo prima la invocación latina, y en "muy pocos" casos aparece en caste llano; ibidem.

Aficiones y devociones en el antiguo régimen

Hispania Sacra 50 (1998) 
variedad de misterios aludidos - hasta siete-, de fórmulas únicas empleadas y una mayor complejidad de cláusulas de $\mathrm{fe}^{32}$.

La importancia de la cláusula de solicitud de intercesores, contrariamente a la situación mostrada por los testamentos gaditanos, radica en que se mantiene en los mismos parámetros de universal generalización que otros formulismos religiosos ${ }^{33}$. El número de peticionarios de intercesión asciende al $99 \%(100 \%$ entre las féminas). En consonancia con las valoraciones vertidas anteriormente, el interés por la salvación y el miedo a la muerte y al infierno conducen irremediablemente a los otorgantes a pensar en las recomendaciones de la Iglesia de acudir a aquellos de entre la corte celestial que más poder mediador tengan ante Dios: la Virgen María, el Ángel de la Guarda y los Santos de la devoción personal, básicamente el patrón de la buena muerte, San José.

\section{A. Inmovilismo formal: cambios y permanencias.}

El inmovilismo clausular de las fórmulas notariales a lo largo del Antiguo Régimen y tanto en las áreas rurales castellanas como en la capital vallisoletana es patente.

Muchas escrituras del periodo 1830-1834 alumbran estas "permanencias", extensibles durante mucho más tiempo a los ámbitos no urbanos. Un matrimonio declaraba: "Santísima Trinidad, tres personas distintas que tienen los mismos atributos y son un solo Dios verdadero y real y una esencia y substancia... para evitar los cuidados temporales que nos obsten y embaracen pedir a Dios de todas veras la remisión que esperamos de nuestros pecados" 34 . Un escribano del número, "cuando tan terrible lance llegue las que tenemos no me embaracen y distraigan de las espirituales, la Siempre Virgen María, Madre de Dios y Señora Nuestra, Angel de mi Guarda, Santos de mi nombre, devoción y cortesanos todos del cielo, se apiaden en aquel justo y recto tribunal, en remisión de mis culpas terrenales, a que mis culpas la sujetan, bajo tan sublime manto de

32 Al lado del misterio de la Santísima Trinidad, aparecen los del Santísimo Sacramento del Altar, la Encarnación del Verbo Etemo, la Pasión y Muerte de Cristo y su Resurrección, la Ascensión y Subida a los Cielos, el Juicio Final, el misterio de la Cnuz o el de la Inmaculada Concepciơn. También encuentran testamentos cerrados muy completos junto a alusiones muy comprometidas con la fe y con el rechazo a Ja herejía (“...detesto, condeno y anatematizo todo lo que condena, anatematiza y detesta la Santa Madre Iglesia"); Roberto J. López, ob. cit., pp. 55-56, y M José de la Pascua, ob. cit., pp. 96-98.

$33 \mathrm{M}^{2}$ José de la Pascua, ob. cit., pp. 102-103.

Únicamente cuatro omiten la abogacía celestial en el Valladolid de 1750. José Pérez, el mercader Pedro Ribera, Don Andrés González, alférez de infantería y Ambrosio Mañanes.

34 A.H.P.V., Secc. Prot., Leg. 11986, ff. 90-92 (Valladolid, 1833). 
precaucion y amparo..."35. Muchos invocaban a toda la corte celestial para que " $^{36}$ "impetren a Nuestro Señor por el perdón de mis culpas, y goce de su benefica presencia;... temiendome de la muerte y para estando prevenido resolver con maduro acierto y reflexion todo lo concerniente al descargo de nuestras conciencias, evitar con claridad las dudas y pleitos que por su defecto se pudieran suscitar, y así no tener cuidados temporales a la hora de mi muerte, pido perdon a Dios y remision de mis pecados y me encomiendo al Sagrado Arbol de la Cruz". Enumeración que podría ser mucho más amplia ${ }^{37}$.

Incluso, aparecieron fórmulas de estilo más extensas ("únicas") que a mediados del siglo precedente. Una mujer (casi todas las que citamos lo eran), profesaba su creencia "en la Encarnación y Nacimiento de No. Señor JesuCristo y en su Sagrada Pasión y Muerte, Resurrección y Ascensión a los Cielos, y en lo que además cree la Santa Madre Iglesia, como Dios lo ha revelado y ella nos lo enseña;... Nuestra Señora, la Virgen Santísima María, Madre de Dios, Reina de Cielos y Tierra, el Angel de la Guarda, el Santo de mi nombre y los demás Santos de la Corte celestial, me amparen en la terrible hora y lance de la muerte"38. Un escribano "ruega al Ser Supremo Dios Omnipotente aparte sus ojos de mis pecados y recoja mi alma en su Sta. Gloria para que eternamente le alabe y bendiga, objeto para que la crí́ y redimió" 39 . Otra viuda, "acordandome que naci para morir, temiendome de la muerte que es cosa natural a toda criatura viviente, porque no me coja la muerte descuidada, asi en la disposición de mi alma y descargo de ella como en la disposicion de mi hacienda, que mi Dios ha sido servido de darme, me tenga en su bendita mano y conserve en su gracia para que acabando en ella me de su gloria...", creía, pedía intercesores para ponerse en la Carrera de la salvación, se encomendaba a la Divinidad y deseaba "cuando llegue el último instante de mi vida estar dispuesta con disposición testamentaria que me lleve a gozar de su vida eterna"40. Una tercera, "considerando la fragilidad de la vida y que la muerte, en que

\footnotetext{
35 A.H.P.V., Secc. Prot., Leg. 15730, ff. 55-57 (Valladolid, 1833).

36 A.H.P.V., Secc. Prot., Leg. 5145, ff. 84-88 (Valladolid, 1834).

37 Frases como "por sus méritos me perdone lo mucho que le he ofendido y dirija esta disposición a su mayor agrado", "perdone mis culpas y ofensas", "deseando estar prevenido y recelándome y temiendo a la muerte", "para estar preparado para la Carrera de la Salvación", "para descargo de mi conciencia", "lleve mi alma a gozar de su Beatífica presencia", "perdone mis pecados, y me de luz y acierto para hacer mi testamento", "de corazón" ruego intercedan con Dios Nuestro Sentor para que me perdone mis culpas y pecados o "deseando tener arreglados mis asuntos temporales para cuando llegue la muerte, cosa natural, no me coja desprevenido de los cuidados temporales y poder atender mejor a la salvación de mi alma", se repetían con total asiduidad; todos en A.H.P.V., Secc. Prot., Legs. 12051 y 4321 (Valladolid, 1833-1834).

38 A.H.P.V., Secc. Prot., Leg. 4323, ff. $91-92$ (Valladolid, 1832).

39 A.H.P.V., Secc. Prot, Leg. 4330, ff. 279-280 (Valladolid, agosto 1834).

to A.H.P.V., Secc. Prot, Leg. 5807, ff. 183-184 (Valladolid, marzo 1830).
}

Aficiones y devociones en el antiguo régimen

Hispania Sacra 50 (1998) 
todos incurrimos por el pecado de nuestros primeros padres, me encuentre despojada de cuidados temporales para mejor atender a la salvacion de mi alma y para mayor servicio de Dios", invocaba a la "concebida en plenitud de gracia en el instante primero de su animado ser" y hacía la más solemne protestación de fe como católica y fiel cristiana ${ }^{41}$.

La importancia de estas cláusulas radica en que se mantuvo en unos parámetros de universal generalización ${ }^{42}$. El miedo a la trasmuerte condujo irremediablemente a pensar en las recomendaciones de la Iglesia de acudir a aquellos cortesanos celestiales que más poder mediador tuviesen ante Dios. Así, cada testador solicitaba, como media, 5,3 intercesores.

En esas fechas del siglo XIX un $22 \%$ de los testadores dejaban ya sin encabezamiento religioso sus actas de últimas voluntades. Aunque en buena parte se deba a los efectos producidos por el cólera morbo y a la urgencia por dar soluciones rápidas a los aspectos relacionados con la muerte epidémica, también simboliza el cambio de los tiempos, cuando aún en 1800 estos conceptos introductorios seguían siendo mayoritariamente redactados.

En aquel cotexto de estabilización de estilos heredados, las fórmulas de encabezamiento se mantuvieron constantes en el tiempo y en el espacio (tampoco se advierten comportamientos diferenciales por sexos). Inmovilismo, acompañado de algunas puntualizaciones de interés y no exento de variantes geográficas y evolutivas. Profesión de fe, petición de intercesores y encomendación, por ser formulismos notariales, apenas modificaron sus términos durante tres centurias. Incluso en las zonas rurales y mediado ya el siglo XIX esos exponentes de la mentalidad colectiva no habían sufrido alteración alguna ${ }^{43}$.

41 A.H.P.V., Secc. Prot., Leg. 4384, ff. $77-78$ (Valladolid, 1831).

Como en los ejemplos anteriores, otros casos redundan en ese carácter religioso introductorio, a la vez que testimonian mayores preocupaciones econ6mico-hereditarias: "resolver con maduro acierto y acuerdo todo to concerniente al descargo de mi conciencia, evitar con la claridad las dudas y los plcitos que por su defecto pueden suscitarse y no tener a la hora de la muerte ningun cuidado termporal que me obste pedir a Dios con todas veras la remisión que espero de mis pecados", A.H.P.V., Secc. Prot., Leg. 5811, ff. 211-212 (Valladolid, 1832); o "disponerme para cuando llegue la muerte, y hallarme desembarazado de las cosas que pudieran impedirme emplearlo todo a Dios Nuestro Señor", A.H.P.V., Secc. Prot., Leg. 4379, ff. 256-257 (Valladolid, 1833).

42 Vid. $M^{a}$ José de la Pascua, ob. cit., pp. 102-103. Esta fórmula en Cádiz tenía menor peso y tendió a debilitarse y cmpobrecerse a medida que avanzaba el siglo XVIII: en 1700 aparecía en el $66,1 \%$ de los testamentos, para descender hasta un $45,9 \%$ en 1750 .

43 Algunos ejemplos confirman la amplitud del mantenimiento de todo ese preámbulo religioso introductorio. Como los testamentos de Don Jerónimo García Paredes, beneficiado de evangelio de Monroy, A.H.P.V., Secc. Prot., Legs. 3462-3463, ff. 4-13 y 31 1-317 (Tudela de Duero, 1751-753); el del también cura propio de Fuente el Olmo, Don Francisco Mantilla de las Cuevas, 10484, ff. 18-19 (Iscar, 1701); el de Don Manuel Núīez Gamarra, beneficiado de preste de Curiel, 14649, ff. 21-24 (Curiel, 1702); otro cerrado de Don Juan Ignacio Perotes, 14660, ff. $51-61$ (Curiel, 1750); el del preste y comisario del Santo 
La Virgen María fue invocada siempre. Los cortesanos del cielo eran requeridos por una gran mayoría. La protección del Custodio se buscaba y demandaba con asiduidad. La solicitud de abogacía al conjunto de los mediadores celestiales era un recurso frecuente.

La invocación a la intercesión Mariana primaba sobre el resto. Desde Trento, la figura de la Virgen María se revalorizó, y su devoción ascendió en las centurias posteriores ${ }^{44}$. Tọdos cuantos solicitaron protección de lo Alto

Oficio de Piñel de Yuso, Don Gaspar Fuentes Femández, 14683, ff, 82-85 (Curiel, 1798); el del catedrático de filosofia de Oviedo y cura de Valoria, Don Juan Antolino y Azogue, 14920, ff. 69-73 (Valoria, 1752); el del presbítero, Don Francisco Lopez Burgueño, 14585, ff. 195-200 (Esguevillas, 1796); el cerrado del presbítero, Don Alonso Luengo, 5234, ff. 42-45 (Tordesillas, 1701); el también cerrado del escribano del número de Población de Cerrato, Don Alejandro Ordejón Fenández, 11790, ff. $24-29$ (Cevico, 1704); el del tendero y familiar del Santo Oficio, Lorenzo de Dios Escudero, 9221, ff. 81-87 (Rioseco, 1703); el del clérigo, Don Joaquín Martínez, 9297, ff. 73-89 (Rioseco, 1752); y el del también beneficiado del cabildo eclesiástico, Don Antonio Fernández Corralón, 9315, ff. 145-152 (Rioseco, 1750).

La viuda ceviqueña Ana Calzada, declaraba: "deseando antes del último accidente de mi vida disponer mi testamento con el acierto y sosiego que pide materia tan grave y de tanta importancia... cree en los Santos Sacros misterios de la Incomprensible y Santisima Trinidad, Encamacion de Verbo Eterno en las purisimas entrañas de la Virgen Santisima, Madre de Nuestro Sentor JesuCristo, en el Santisimo Sacramento del Altar y en los demas que cree y confiesa la Santa Madre Iglesia; imploro el auxilio y amparo e intercesión y patrocinio de María Santisima, Madre Nuestra, Angel de la Guarda y los demas Santos de la Corte Celestial", A.H.P.V., Secc. Prot., Leg. 11185, ff. 5-6 (Cevico de la Torre, 1795).

44 Los textos de las Sinodales vallisoletanas de 1606 son expresivos y contundentes del valor protector y de patronazgo que Ella ejercía sobre su Iglesia. Constituciones Sinodales Vallisoletanas, Tít. I, Lib. 1, p. 22:

"quiso Dios que las intercesiones de sus Santos valiesen con su Divina Majestad para hacernos mercedes, y así, acudiésemos a ellos con nuestras peticiones para que las presentasen ante $\mathrm{El}$, $y$ por sus meritos e intercesion nos concediese lo que le pidiesemos. Entre todas las puras criaturas, Nuestra Seffora es la principal en santidad, honor y merecimiento con incomparables ventajas, por ser la más llena de gracia, la que más amó, sirvio a Dios y cumplió más entera y perfectamente sus mandanientos... y así es su intercesión más afecta y eficaz para alcanzar de Dios lo que se le pidiere: y así la Iglesia con mucha razón la hace oración particular como a la principal patrona y abogada de todos los hombres, madre de Dios y reina del Cielo".

Felipe IV dio fuerza de ley al establecimiento de la devoción al "Rosario de Nuestra Señora" en 1655, por los beneficios espirituales -y materiales que de su asiduo rezo se derivaban, como siempre manifestaron las Cortes Castellanas- que revertirían a toda la comunidad (Novisima Recopilación, Ley XXI, Tít. I, Lib. I). Ley precedida por otra, sancionada por Carlos III, que aseguraba el universal patronato de Nuestra Seb̂ora en el Misterio de su Inmaculada Concepción sobre todos los Reinos de España e Indias; su texto extractado es el siguiente:

"conformando mi religioso zelo y devocion al Misterio de la Inmaculada Concepción de la Virgen Santísima Nuestra Señora... condescender a la súplica de [mis Reinos y vasallos], tomando como tomé por singular y universal Patrona y Abogada de todos mis Reynos... a esta Soberana Señora en el referido Misterio..., sin perjuicio del Patronato que en ellos tiene el Apostol Santiago": ibidem, Ley XVI, Tít. I, Lib. I. Su Santidad el Papa aplaude la decisión de la Corona espanola: “...a los que imploran el auxilio y protección de la ínclita Reina de los Cielos... al extremado

Aficiones y devociones en el antiguo régimen

Hispania Sacra 50 (1998) 
mencionaron a María Santísima, con algunas de las advocaciones para designar a la Madre de Dios, pidiéndole utilizase todo su poder mediador en aras a la remisión total de sus pecados y la consecución de la Gloria Celestial ${ }^{45}$.

María podía llenar por sí sola todo el mundo escatológico rural, aunque a medida que iba transcurriendo el siglo XVIII solía verse arropada con el resto de intercesores aventajados. En la zona de Curiel quedaba bien definida tal realidad: descenso de la imploración a María en solitario o acompañada de los santos de devoción, para incrementarse su mediación rodeada además del santo del día del óbito, del nombre bautismal y del ángel de la guarda.

Partiendo de cotas porcentuales muy elevadas durante el apogeo barroco, el recurso a las devociones y al guardián personal se incrementó considerablemente al ir desgranándose la centuria decimoctava. Los datos más anómalos respecto a esta tendencia secular son los vallisoletanos de comienzos del siglo XVIII. Con todo, en la capital la evolución presenta perfiles similares a los detallados, hasta marcar la pauta general. En Cigales, Peñafiel o Medina de Rioseco esta realidad aparecía más contrastada.

En la esfera de una mayor concreción petitoria, la Serenísima Reina de los Angeles y Hombres cubría parte del catálogo devocional. Su concepción inmaculada fue adquiriendo progresivamente una mayor importancia redentora, junto a sus ya clásicas denominaciones laudatorias y de intermisión. Por el contratio, el recurso al "Soberano Dios y Señor Jesús Nazareno" era minoritario, salvo en los pueblos circundantes de Valladolid a comienzos de la centuria y en la propia capital hacia 1830; se profesaba su fe y a Él se encomendaban todos los castellanos, pero como juez supremo no le consideraban el mediador más cercano.

Estaba a la cabeza de la corte celestial por ser, ante todo, la Madre del Redentor ${ }^{46}$. Más del $90 \%$ de las peticiones de intercesión mariana se encabezaron con "la Serenísima Reina de los Angeles" como mediadora principal"47; completándose su rango de realengo con otras expresiones similares que ampliaban su poderío desde el Cielo a la Tierra. Estos calificativos representaron el

culto de los españoles para con la Madre de Dios... confirmar y aprobar el Patronato de la Santisima Virgen en el sagrado misterio de la Inmaculada Concepción".

45 Contrariamente a estos porcentajes del cien por cien, el comportamiento provenzal fue radicalmente opuesto: la presencia de la Virgen era del $80 \%-85 \%$ a principios del siglo XVIII, reduciéndose al 24,3\% a finales; vid. M. Vovelle, Pièté baroque et deschristianisation en Provence au XVIIIe siècle, París, 1973, p. 151.

46 "Madre del Verbo Divino y de Nuestro Señor y Redentor JesuCristo, Dios y Hombre verdadero", pero también "Madre Nuestra" y "de todo católico christiano".

47 "Señora Nuestra" alcanzaba el 23,2\%, "Serenísima Reina de los Angeles [y Hornbres]" un $24,9 \%$, "Santísima" el 19\%, "Madre de Dios" un 17,8\% y "Virgen Maria" el $8,7 \%$ del total de invocaciones marianas. 
$14,6 \%$ del cúmulo de las intercesiones solicitadas. También aludían a su virginidad, siempre al lado de su concepción inmaculada; mientras otros apelativos teológicos y devociones nacionales o locales tampoco se olvidaron a la hora de solicitar su ayuda ${ }^{48}$. Eran sólo distintos adjetivos que calificaban el fortísimo poder redentor y mediador a Ella atribuído; y que no aparecían aislados, sino que solían encadenarse: como mínimo, tres de ellos siempre. La mediación de todas sus advocaciones constituyó el $60 \%$ de los patrocinios implorados. Con todo, no fueron las únicas mediaciones requeridas.

San Miguel, San Gabriel, San Rafael y "todos los Angeles y Querubines del Cielo", eran aclamados para salir en paz de esta vida. Aunque su relieve cuantitativo fuese muy reducido, muestra el plantel de àrcángeles más enraizado en la mentalidad colectiva popular, sin duda por su papel de exterminio del mal y de contacto con lo terrenal; informando también de la consideración de los ángeles como almas puras, bondadosas y cercanas a la divinidad, que podían defender armados y alcanzar la misericordia de Dios para los humanos. Así, San Miguel fue el arcángel "bélico" más popular.

El Ángel de la Guarda proporcionaba toda la entidad a este grupo de medianeros. La creencia en su existencia y en su capacidad de compañía, amparo y protección ante los peligros del mundo fue creciendo paulatinamente. Originó su fuerte peso como intercesor privilegiado y que la invocación al Ángel Custodio fuese mayoritariamente solicitada ${ }^{49}$.

El Apostolado era menos recordado en la hora de la muerte. Expresaron la esperanza en los doce patriarcas, como acompañantes de Cristo en la tierra, centrándose en sus dos cabezas más visibles, San Pedro y San Pablo. Tal inseparable binomio concitaba la mayor cantidad de demandas de misericordia: portería del cielo y tranformación vital, les convirtieron en modelos a imitar y con quienes tener "buenas relaciones". Las mujeres de Tordesillas y Portillo (de todo el agro castellano) les requirieron con una insistencia cada vez mayor, hasta minimizar al resto del santoral.

48 "Amparo, refugio, protectora y abogada de pecadores y consuelo de afligidos, enfermos y agonizantes", "Madre Piadosa", "Virgen Gloriosa", "Princesa de los Cielos", "Misericordiosa", "Llena de Gracia", "de los Dolores", "del Carmen", "Patrona de Esparra", "con el admirable renombre del Santísimo Rosario, cuya fiesta se celebra hoy", "del Pilar", "Nuestra Señora de Viloria" o "de la Peña đe Francia".

Recuérdese: Nuestra Señora de la Esperanza, de San Lorenzo, de los Remedios, de la Asuncion, del Rosario, del Carmen ("del Monte Carmelo, mi señora y abogada, por cuyo medio espero mucho de su piedad"), de la Purificación, del Amparo, de los Dolores, de la Soledad, de la Estrella, de la Soterrafia, de Valbanera...

49 Constituciones Sinodales Vallisoletanas, Lib. I, Tít. I, Parte V, p. 63.

Aficiones y devociones en el antiguo régimen

Hispania Sacra 50 (1998) 
Los Santos de la Corte Celestial aparecían en lugar preferente, poniendo de manifiesto las devociones más íntimamente personales; aunque éstas sólo las explicitasen unos poco, al reducir la gran mayoría su solicitud medianera a "todos los santos de la corte celestial" invocaciones requeridas a mediados del siglo XVIII, lo que ratifica su valor de intermediación.

"Santo de mi nombre, santos de mi devoción y todos los demás de la corte celestial" fue la fórmula más empleada. Se acudía al santo "que lo es de mi nombre, cuyo nombre merecí por tan glorioso en el bautismo" o "al santo del día, cuya fiesta se celebra hoy" y, también, a los de mi devoción o "a todos los santos que en el discurso de mi vida me cayeron en suerte", pero siempre como un arquetipo formulístico, demostrativo de la universalización totalizadora del plantel de intercesión.

Pocos fueron los peticionarios y escasos los santos nominados. Los hombres demandaron más al santoral, pero fueron las mujeres quienes más santos reclamaron cada una. Muchos de ellos (Santo Domingo, Santa Teresa, San Antonio Abad, San Ignacio de Loyola, San Juan Evangelista o Bautista, Santa Inés, San Benito, San Judas Tadeo, San Cayetano, Santo Tomás, San Francisco Javier, San Pedro de Alcántara, Santa Clara o Santa Agueda) únicamente aparecían una o dos veces, y su valor, por tanto, era sólo referencial; aunque su asiduidad como nombre propio les confiriese su auténtica consideración patronal.

San Joaquín y Santa Ana, dada su condición de paternidad sobre la Virgen, aparecían siempre juntos en las intercesiones. También el convento franciscano, como uno de los más poderosos, numerosos, presentes en la vida urbana, mejor relacionado con los gremios y situado en pleno centro, hizo de su patrón un buen mediador.

Los más solicitados fueron San José, San Antonio de Padua y San Pedro Regalado; constituyéndose en alguno de los más presentes en el universo mental de los vallisoletanos del siglo XVIII, por su "calidad" y veneración castellano-nacional.

El glorioso patriarca San José, cuya devoción se fue extendiendo desde el siglo XVIl, era el patrón de la buena muerte y, "como esposo castísimo de la Virgen María y padre adoptivo de nuestro Señor Redentor JesuXto. siendo hombre", su dignidad era superior a la del resto, y así también su valimiento y

50 El recurso al santoral siempre fue obligado en momentos dificiles. Las creencias populares se sustentaban en los muchos soportes de ultratumba que intervenían sobre los hechos terrenales. Siempre habia un santo en la boca del castellano; en una de sus festividades se nacía y en otra se moría.

"Santos de la Católica Iglesia", "demás Cortesanos del Cielo" o "y a los demás Santos de la Corte Celestial que están gozando de la visión beatífica de Dios". 
VII. FORMULARIO RITUAL DEL ENCABEZAMIENTO TESTAMENTARIO. SOLICITUDES DE INTERCESIÓN. Provincia de Valladolid. 1650-1834.

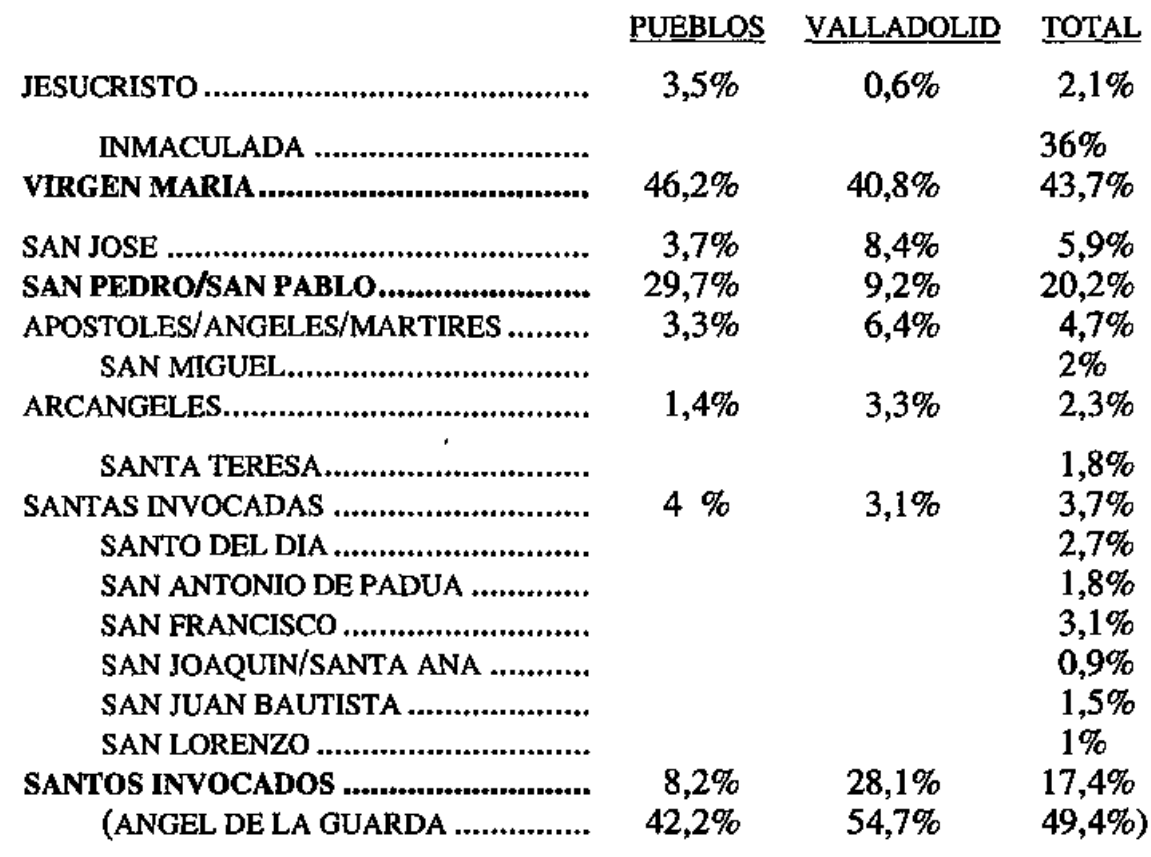

patrocinio fue el más seguro, poderoso y universal: constituía la cuarta parte del santoral invocado ${ }^{51}$. San Antonio de Padua era el patrón tutelar del gremio de sastrería y de los tejedores de lana, y en su calidad de santo patriarca con poderes salvíficos contaba con estima y simpatía entre todo el pueblo. Tampoco podía faltar San Pedro Regalado, el santo de Valladolid por excelencia; su calidad de santo local (canonizado a mediados del Setecientos) le alzaba a los altares y era considerado un inmejorable intercesor ante la divinidad ${ }^{52}$.

5I San José fue el de "muerte más santa", rodeado de María y su Hijo. Por eso, en él se centraron las predilecciones en la última hora durante todo el Antiguo Régimen. Era muy recordado en Valladolid, pero también en Iscar o Medina del Campo.

52 Recuérdense las fastuosas fiestas 'del siglo' de Valiadolid, trasgrediendo incluso lutos reales, que se produjeron tras la canonización y patronato del Regalado (1745-1747). Un coetaneo, Ventura Pérez, en su Diario de Valladolid, las dejó reflejadas espléndidamente (básicamente, pp. 245-257). Vid. también, M. Sangrador Vítores, Historia de la muy noble y leal ciudad de Valladolid, Valladolid, 1979, p. 504; y G. Marcilla Sapela, Datos para la historia de Valladolid (siglo XVIII), pp. 93 y ss..

Aficiones y devociones en el antiguo regimen Hispania Sacra 50 (1998) 
Constantemente presentes, nunca fueron olvidados porque siempre estuvieron muy próximos y cerca de los mortales. Más en la ciudad; con mayor insistencia en el siglo XVII que con posterioridad, pero su carácter mediador nunca se perdió: los datos de Iscar, Medina del Campo, Olmedo o el Valladolid de 1800 lo confirman ${ }^{53}$. Además, nótese cómo unos pocos nombres del santoral, siempre los mismos (y los mismos con los que se bautizaron los testadores), se reiteraban con total asiduidad. Los de Padua y Asís, Santa Teresa de Jesús, los abuelos del Salvador, el Bautista y San Lorenzo se encuentran entre los más renombrados ${ }^{54}$. Su presencia social estaba arraigada: muchas personas los llevaban como nombre de pila o colgaban de las paredes de sus casas. Al ser su "medicina espiritual" la más eficaz, la reverencia a su advocación se multiplicaba.

En conclusión, este rasgo arquetípico muestra el continuismo de los formulismos de estilo, definitorios de unos ritos funerarios que se mantuvieron arraigados durante mucho tiempo en las conciencias y en las plasmaciones concretas externas de muchos castellanos, aunque sabemos que definir la velocidad

Entusiasmo popular y símbolo de abogacía reflejado perfectamente cuando, entre 1709 y 1750 , a más del $65 \%$ de bautizados en la parroquia de El Salvador se les puso por abogado a San Pedro Regalado; vid., T. Egido, "La Religiosidad colectiva de los vallisoletanos", Valladolid en el siglo XVIII, Valladolid, 1984, p. 217.

53 Entre otros muchos: A.H.P.V., Secc. Prot., Leg. 10104, ff. 52-66 (Pefiaflor de Homija, 1753), testamento de Don Ignacio García Ortega, beneficiado de preste de Peñaflor.

54 Algunos ejemplos: "Inmaculada siempre Virgen María, San Juan Bautista, San José, San Francisco de Asís, Santo Domingo de Guzmán, San Francisco de Paula, San Antonio de Padua, San Ignacio de Loyola, San Francisco Javier, San Pedro de Alcántara y Santa Teresa de Jesús", A.H.P.V., Secc. Prot., Leg. 10484 (Iscar, 1700). "San José, San Antonio Abad, San Agustín, San Francisco de Paula, San Buenaventura, San Nicolas Tolentino, San Ignacio y San Francisco Javier", A.H.P.V., Secc. Prot., Leg. 2681 (Valladolid, 1702).

Otros muchos más muestran la concreción del santoral invocado, junto a las preferencias personales. "Santa Ana, San José, San Joaquín, San Alejandro y San Miguel" (Cevico, 1702). "San Fran cisco, San Antonio, San Vicente Ferrer y San Cayetano" (Valladolid, 1701). "San Jose, San Juan Bautista, San Felipe Neri, San Francisco y San Antonio" (Valladolid, 1798). "San Miguel, San José, San Francisco y Santo Domingo" (Valladolid, 1799). “San Miguel, San José, San Juan Bautista, San Juan Evangelista, San Pedro, San Pablo y todos los Santos patronos y justos Apóstoles, Mártires, Confesores y Vírgenes" (Valladolid, 1651). "San Pedro, San Pablo, San Luis de Francia, San Miguel, San Francisco, San Antonio de Padua, Santa Catalina Alejandra y San Antonio Abad" (Valladolid, 1650). "Santo Domingo Soriano, San Francisco, San Juan Bautista y San Juan Evangelista" (Valladolid, 1654). "San Pedro, San Basilio, San Antonio de Padua y San Miguel" (Valladolid, 1653). "San José, San Francisco, Santo Domingo y San Antonio de Padua" (Valladolid, 1652). "San José, San Pedro, San Francisco y Santa Isabel" (Portillo, 1702). "San Agustín, San Antonio de Padua, la Mag" dalena, Santa Ana y Santa Teresa de Jesús" (Peñafiel, 1799). "San Francisco de Asís, San Antonio de Padua, Santa Rosa de Viterbo y San Juan de la Cruz" (Olmedo, 1751). "San José, San Joaquín y Santa Ana, San Pedro y San Pablo, San Juan de Dios, Santa Teresa de Jesús, San Antonio de Padua y San Lorenzo" (Medina de Rioseco, 1702). "San Joaquín y Santa Ana, San Antonio de Padua y San Nicolás de Bari" (Medina de Rioseco, 1753). A.H.P.V.. 
de la evolución de la mentalidad durante este largo periodo antiguorregimental a través únicamente de este rasgo notarial oculta vertientes importantes de la tranformación ideológica experimentada por una amplia colectividad.

\section{LOS HÁBITOS RELIGIOSOS: LAS MORTAJAS FUNERARIAS.}

Su evolución ${ }^{55}$, desde la sábana-sudario o las vestiduras ordinarias, provocó que los hábitos de las distintas órdenes mendicantes fuesen enfundados por los fallecidos: fenómeno urbano primero, se generalizó rápidamente entre todos los grupos sociales después. En el siglo XVIII, los escapularios con poder taumatúrgico o la doble mortaja no eran infrecuentes; la costumbre de comprarlos en vida y con salud, tras su bendición, tampoco.

El miedo inspirado por el Juicio Final provocaba actitudes de preparación y la utilización de todo tipo de remedios píos. Humildad y consecución de "días" de perdón se encontraban en el origen de la universalización de este recurso ritual y de búsqueda de "seguridades espirituales". Establecida la necesidad de la demanda, la pugna entre ordenes religiosas por ofrecer muchas indulgencias a sus hábitos y escapularios era comercial, pero también de presencia y control social. Acudían al más próximo o a quien ofreciese más garantías; la mejor solución, para quienes pudieran costearla, era la doble mortaja.

PETICIÓN DE HÁBITOS DOBLES. Provincia de Valladolid: 1650-1834.

$\begin{array}{lrr}\text { San Francisco - Nuestra Señora del Carmen } & 48 & 52,8 \% \\ \text { San Francisco - Sacerdotal } & 10 & 11 \% \\ \text { San Francisco - Santo Domingo } & 11 & 12,1 \% \\ \text { San Francisco - Otros } & 11 & 12,1 \% \\ \text { Nuestra Señora del Carmen - Otros } & 7 & 7,7 \% \\ \text { Otros Dobles } & 4 & 4,4 \%\end{array}$

Buena parte de los fallecidos dejaron constancia de su intención de ser enterrados con mortaja funeraria; incluso, en número creciente durante el siglo XVIII. Incremento progresivo de la demanda hasta convertirse en práctica-

$55 \mathrm{M}$. Vovelle advierte que en las zonas nurales provenzales se mantuvo durante mucho más tiempo el tradicional sudario; vid. ob. cit., p. 83. A. Tenenti también ha formulado perfectamente "el horror medieval a la miseria del cuerpo", de donde parte el deseo de envolver su putrefacción; vid. Los fundamentos del mundo moderno, Barcelona, 1985. Véase también: Domingo González Lopo, "Actitud ante la muerte en la ciudad de Santiago durante los siglos XVII y XVIII: la actuacion de las ordenes mendicantes", Liceo Franciscano, 1985, pp. 147-165.

Aficiones y devociones en el antiguo régimen

Hispania Sacra 50 (1998) 
mente general. En Valladolid y su area circundante tal incremento fue continuado y sostenido: desde los bajos índices barrocos de partida (inferiores al $45 \%$ ), hasta alcanzar los máximos a finales de la centuria decimoséptima y/o sólo disminuyendo desde entonces. Cuando en 1650 más del 55\% descuidaba tal elección, aún en 1830 ese mismo porcentaje seguía eligiendo personalmente una mortaja, y sólo tras haber descendido desde el $90 \%$-índice máximo- del periodo finisecular. Fuerte incremento urbano y rural, por tanto; y aunque en el campo se iniciase más tardíamente, su progresión también fue más acelerada, hasta superar las tasas urbanas y mantenerse durante mucho más tiempo.

VIII. PRINCIPALES HÁBITOS SOLICITADOS COMO MORTAJA FUNERARIA. VALLADOLID Y PUEBLOS. 1650-1834. Porcentajes.

\begin{tabular}{|c|c|c|c|c|}
\hline & TOTAL & VALL & PUEBLOS & $\underline{1650}$ \\
\hline RANCISCANOS . & 62,8 & 57,3 & 69,9 & 66,7 \\
\hline 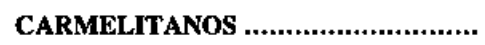 & 27,3 & 23,6 & 14 & 6,3 \\
\hline 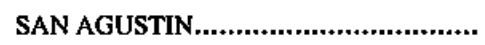 & 3,1 & 0,7 & 6,1 & 3,5 \\
\hline STRA SEÑORA DE LA MERCED .. & 0,6 & 0,9 & 0 , & \\
\hline O DOMINGO & $1, \mathrm{C}$ & 1,4 & 1,8 & 3,1 \\
\hline 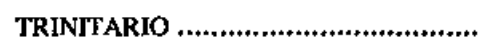 & 0,8 & 1 & 0,5 & 1,5 \\
\hline OS NO RELIGIOSOS...................... & 3,8 & 15,1 & 7,4 & 17,8 \\
\hline
\end{tabular}

El hábito de San Francisco era el más "popular". Popularidad de la orden, extensión de su Orden Tercera y sus numerosas indulgencias, le convirtieron en el más requerido. Junto a él, el resto de los hábitos religiosos tuvieron una menor presencia (el mercedario, dominico o agustino), aunque el carmelitano fuese uno de los más arraigados entre las mujeres.

\section{INHUMACIÓN DEL CADÁVER: ESPACIOS Y RITUALES SACRALIZADOS.}

Hasta 1833 Ia realidad sacralizada del enterramiento no se transformó definitivamente. De los espacios sagrados se pasó entonces a las ciudades de los muertos: municipales y alejadas del vecindario. En Castilla, las parroquias se habían convertido en osarios, pero también claustros y recintos conventuales contenían un $10 \%$ de los cadáveres de los vallisoletanos ${ }^{56}$.

56 El dimorfismo queda patente entre los $13,5 \%$ y $3,5 \%$ presentados por las zonas urbana y rural: la proporción era de ocho a dos para quienes se mandaron enterrar en monasterios capitalinos $(8,1 \%$ 
Desde posiciones de desahogo económico y calando luego en el resto de los estratos sociales, el deseo de soterrarse en los conventos fue ganando adeptos paulatinamente. A mediados del XVII más de una cuarta parte de los testadores así lo manifestaba; desde entonces, el descenso fue progresivo y rápido: en dos siglos la costumbre prácticamente sólo se conservaba en círculos minoritatios $(26 \%, 10 \%, 7 \%, 6 \%$ y $2 \%$ en 1834$)$.

Las preferencias monacales eran rotundas. La orden franciscana (con Dieguitos y Mínimos de la Victoria), con fuerte implantación en Valladolid, Peñafiel, Olmedo y Medina de Rioseco, atrajo bajo sus losas a muchos benefactores y buscadores de un último signo de pobreza. Aunque no sólo de su "atractivo" depenđió la evolución de la sepulturación conventual, frente a la norma general, el porcentaje de los allí enterrados fue in crescendo: básicamente en las zonas rurales y potenciado por la frecuente elección de los varones.

Las Descalzas Reales, San Felipe de la Penitencia, San Joaquín y Santa Ana, Santa Isabel, Santa Clara y San Felipe Neri ${ }^{57}$, en Valladolid, y el monasterio del Abrojo ${ }^{58}$, fueron lugares comunes de depósito postrero, aunque siempre muy por debajo del $40 \%$ de quienes ordenaron su enterramiento en los franciscanos.

Algunos de los conventos con honda implantación social, sin embargo, sólo contaban con una demanda privilegiada, al ser únicamente los miembros más encumbrados de la élite local quienes manifestaban de este modo (y podían pagar) su preeminencia. Los enterrados en San Pablo o en San Benito se encontraban entre ellos. Los de la Merced y Carmelitas (Calzados y Descalzos), Agustinos Recoletos, Clérigos Menores, Santos Mártires y la Santísima Trinidad se situaban en situaciones intermedias de presencia y demanda social.

Más de un tercio de los oidores, regidores, escribanos... y clérigos (y casi el $50 \%$ de los nobles) vallisoletanos, hacia 1750 , así manifestaron su posición jerárquica en la hora de la muerte. Un cincuenta por ciento de quienes designaban un convento, pertenecían a esos grupos sociales, cuando sólo constituían el $23 \%$ de la muestra testamentaria. También comerciantes y mercaderes dirigieron parte de sus fortunas hacia las ordenes mendicantes: destinaban sus

frente al 1,2\%). Sólo en Cádiz los ámbitos conventuales fueron más demandados que los parroquiales (alli se enterraba el 64\% de los gaditanos); vid. María José de la Pascua, ob. cit., pp. 175 y ss..

57 También: la Vera Cruz, los conventos de Nuestra Señora de los Ángeles, Santa Brígiđa, San Quirce, del Espíritu Santo, la Misericordia, el del Corpus Christi, las Lauras, Jesús y María, Capuchinos, Premostratenses, el colegio de San Ignacio, Santa Cruz, los monasterios de Santa Catalina, de la Madre de Dios, Nuestra Señora de Prado (Jerónimos) o de las Huelgas.

58 Junto a los conventos de San Andrés (orden de Santo Domingo), San Francisco, Santa Ana (Carmelitas) o el de la Santísima Trinidad, de Medina del Campo; el monasterio de la Mejorada; Nuestra Seffora de Valbuena; el de Palazuelos; el de la Esperanza de Valdescopezo y los conventos de San Pedro Mártir, el Carmen Descalzo y Santo Domingo, de Medina de Rioseco.

Aficiones y devociones en el antiguo régimen Hispania Sacra 50 (1998) 
EL RECURSO AL SANTORAL EN CASTILLA, DEL BARROCO A LA ILUSTRACIÓN... 169

ganancias a la salvación del alma y a reafirmar su ascenso económico mediante este signo externo, de todos conocido.

IX. El ENTERRAMIENTO CONVENTAL. Valladolid. 1650-1834.

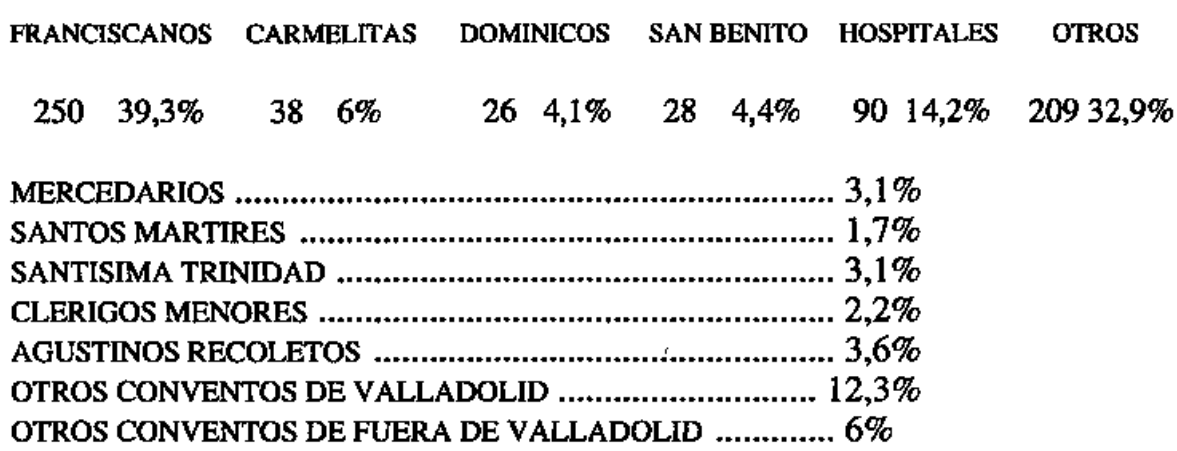

CONVENTOS FRANCISCANOS. Porcentajes.

\begin{tabular}{|c|c|c|c|c|c|c|}
\hline & $\underline{1650}$ & $\underline{1700}$ & 1750 & 1800 & $\underline{1830}$ & TOTAL \\
\hline 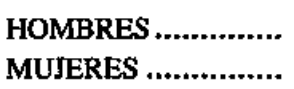 & $\begin{array}{l}32,6 \\
37\end{array}$ & $\begin{array}{l}42,7 \\
37,7\end{array}$ & $\begin{array}{l}36,5 \\
28,6\end{array}$ & $\begin{array}{l}58,1 \\
48,4\end{array}$ & $\begin{array}{l}50 \\
30\end{array}$ & $\begin{array}{l}40,9 \\
37,1\end{array}$ \\
\hline $\begin{array}{l}\text { VALLADOLID .......... } \\
\text { PUEBLOS ................ }\end{array}$ & 35 & $\begin{array}{l}37,1 \\
51,2\end{array}$ & $\begin{array}{l}27,2 \\
64,7\end{array}$ & $\begin{array}{l}48,6 \\
76,2\end{array}$ & 41,7 & $\begin{array}{l}36,4 \\
59,3\end{array}$ \\
\hline OTAL ... & 34,7 & 40,5 & 33,7 & 54,8 & 41,7 & 39,3 \\
\hline
\end{tabular}

La celebración de misas post-mortem constituía otra de las facetas básicas para aquellas mentalidades. Los lugares conventuales donde se solicitaba su oficiamiento, las denominaciones dadas a varios ciclos litúrgicos y muchos de los días de conmemoración de misas perpetuas también muestran el peso del santoral en las vidas y en la muerte durante el Antiguo Régimen, dado que ni la demanda ni su cuantía descendieron. Las tablas adjuntas reflejan los distintos protagonismos sacros entre la población vallisoletana. 


\section{CONVENTOS ELEGIDOS PARA OFICIAR LAS MISAS POST-MORTEM.} VALLADOLID Y PUEBLOS: 1650-1834.

\begin{tabular}{|c|c|}
\hline & NÚMERO de MISAS \\
\hline VALLADOLID CIUDAD. SAN FRANCISCO & 20.646 \\
\hline NUESTRA SEN̄ORA DEL CARMEN CALZADO & 5.813 \\
\hline NUESTRA SEN̄ORA DEL CARMEN DESCALZO & 7.565 \\
\hline CLERIGOS MENORES & 6.173 \\
\hline NUESTRA SEÑORA DE LA VICTORIA & 9.348 \\
\hline CAPUCHINOS & 4.777 \\
\hline SAN PABLO & 7.006 \\
\hline NUESTRA SEÑORA DE LA MERCED DESCALZO & 6.997 \\
\hline NUESTRA SEÑORA DE LA MERCED CALZADO & 4.092 \\
\hline SANTISIMA TRINIDAD & 15.326 \\
\hline AGUSTINOS RECOLETOS & 12.993 \\
\hline SAN DIEGO & 7.128 \\
\hline SAN BENITO & 2.932 \\
\hline SANTOS MARTIRES & 5.786 \\
\hline SAN BASILIO & 1.955 \\
\hline OTROS CONVENTOS DE VALLADOLID & 15.576 \\
\hline SAN FRANCISCO de OLMEDO & 5.410 \\
\hline NUESTRA SEÑORA DE LA MERCED de OLMEDO & 3.861 \\
\hline OTROS CONVENTOS de OLMEDO & 4.574 \\
\hline NUESTRA SEÑORA DE LA FUENSANTA & 3.676 \\
\hline MONASTERIO DE VALDESCOPEZO de MEDINA DE RIOSECO ............... & 2.612 \\
\hline SAN FRANCISCO de RIOSECO & 13.905 \\
\hline SAN PEDRO MARTIR de RIOSECO & 11.070 \\
\hline NUESTRA SEÑORA DEL CARMEN DESCALZO de RIOSECO ........................ & 13.143 \\
\hline NUESTRA SEN̈ORA DEL ABROリ & 3.476 \\
\hline 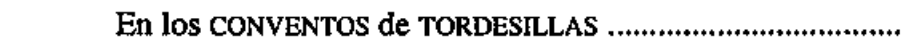 & 2.037 \\
\hline 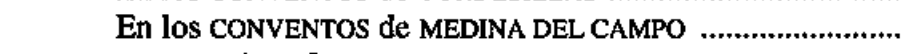 & 5.999 \\
\hline SAN FRANCISCO de PEÑAFIEL & 4.256 \\
\hline 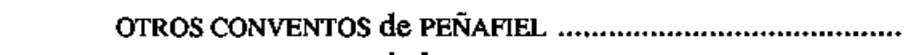 & 1.822 \\
\hline 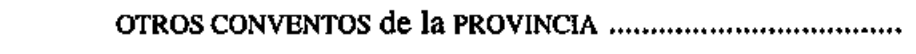 & 4.555 \\
\hline ALTARES DEL MONASTERIO DEL HENAR & 200 \\
\hline DIVERSOS ALTARES de VALLADOLID & 1.797 \\
\hline 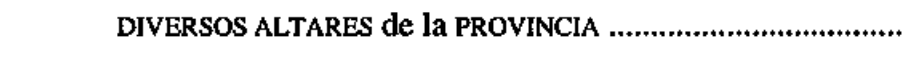 & 2.223 \\
\hline TOTAL & 218.729 \\
\hline PETICIONARIOS (26,44\%; sobre 5.210 demandantes) Media: $160 \ldots$. & 1.378 \\
\hline
\end{tabular}




\section{SOLICITUD DE "MISAS PRETRIDENTINAS". VALLADOLID Y PUEBLOS: $1650-1834$.}

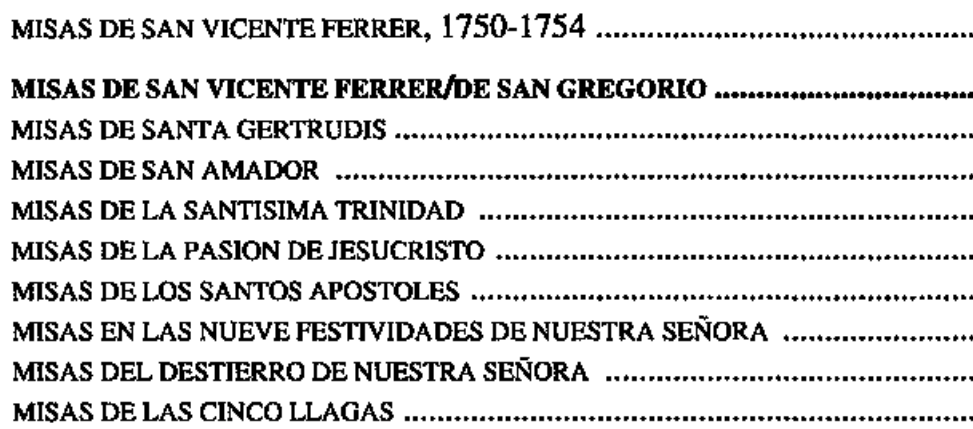

XII. DÍAS DE CELEBRACIÓN DE MISAS PERPETUAS. VALLADOLID Y PUEBLLOS: 1650-1834. Porcentajes.

\begin{tabular}{|c|c|}
\hline EN LAS NUEVE FESTIVIDADES DE NUESTRA SEN̄ORA & $\mathbf{3 0} \%$ \\
\hline INMACULADA CONCEPCION........................... & $5,6 \%$ \\
\hline NUESTRA SEN̄ORA DE LA ASUNCION & $4,2 \%$ \\
\hline NUESTRA SEÑORA DE LA O & $0,9 \%$ \\
\hline NUESTRA SEÑORA DE LOS DOLORES & $0,6 \%$ \\
\hline NUESTRA SEÑORA DEL CARMEN & $1,1 \%$ \\
\hline NUESTRA SEÑORA DEL ROSARIO & $0,4 \%$ \\
\hline OTRAS FIESTAS DE NUESTRA SEÑORA & $2,2 \%$ \\
\hline SAN JOSE & $4,5 \%$ \\
\hline SAN ANTONIO DE PADUA & $2,4 \%$ \\
\hline SAN MIGUEL & $1,3 \%$ \\
\hline SAN FRANCISCO DE ASIS & $3,4 \%$ \\
\hline SAN FRANCISCO DE PAULA & $0,4 \%$ \\
\hline SAN FRANCISCO JAVIER & $0,4 \%$ \\
\hline SAN JUAN BAUTISTA & $3,5 \%$ \\
\hline SAN PEDRO / SAN PABLO & $1,8 \%$ \\
\hline 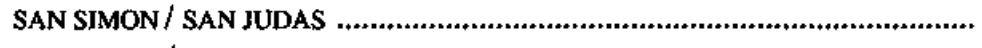 & $0,6 \%$ \\
\hline SAN FELIPE / SANTIAGO & $1,1 \%$ \\
\hline SAN ANDRES & $0,8 \%$ \\
\hline SAN ILDEFONSO & $0,6 \%$ \\
\hline SANTO DOMINGO & $0,4 \%$ \\
\hline AN LUCAS & $0,4 \%$ \\
\hline
\end{tabular}




\begin{tabular}{|c|}
\hline $\begin{array}{l}\text { SAN JERONIMO ....... } \\
\text { SANTOS APOSTOLES }\end{array}$ \\
\hline SANTA ANA ..................... \\
\hline SANTA ANA \\
\hline $\begin{array}{l}\text { SANTA MARIA MAGDALENA } \\
\text { SANTA ISABEL }\end{array}$ \\
\hline SANTA ISABEL \\
\hline SANTA TERESA \\
\hline SANTA CATALINA \\
\hline SANTA INES \\
\hline OTROS SANTOS \\
\hline OTRAS SANTAS ................ \\
\hline
\end{tabular}

DIAS DE LAS FESTIVIDADES DE LA VIRGEN ........................................ $\quad 35,3 \%$

FIESTAS DE LOS SANTOS ................................................................... $45,4 \%$

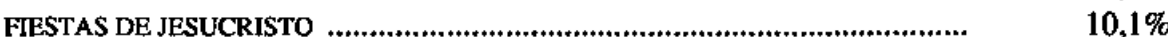

DIA DE TODOS LOS SANTOS .............................................................

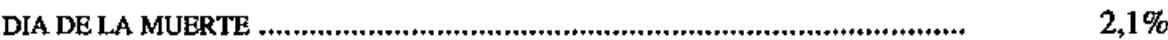

No podía ser de otra manera: en definitiva y en resumen las Cofradías también demostraban el carácter mariano y de búsqueda de patronos celestiales en aquella sociedad castellana de Antiguo Régimen.

XIII. COFRADÍAS DE VALLADOLID CON ADVOCACIONES MARIANAS DEL SANTORAL.

SANTISIMO ROSARIO/NUESTRA SEÑORA DEL ROSARIO Y LA SALUD ........................ 3

NUESTRA SENEORA DE LA PENAA DE FRANCIA .................................................

NUESTRA SEÑORA DE LAS ANGUSTIAS ..............................................................

NUESTRA SENTORA DE LOS REMEDIOS ...............................................................

NUESTRA SEÑORA DE LOS DOLORES Y DEL ROSARIO .............................................. 2

NUESTRA SEÑORA DE LA CONCEPCION ………………………............................ 3

NUESTRA SEÑORA DE LA CONCEPCION Y DEL ROSARIO ……................................ 1

NUESTRA SEÑORA DE LA CONCEPCION DEL CORAZON DE JESUS ...........................

NUESTRA SEÑORA DE LA CABEZA …………….................................................

NUESTRA SENTORA DEL PILAR ...........................................................................

NUESTRA SEÑORA DE LA NATIVIDAD ..................................................................

NUESTRA SEÑORA DE LA SOLEDAD .......................................................... 4

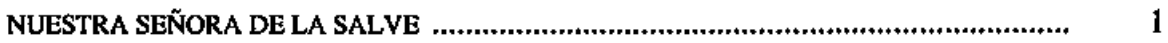

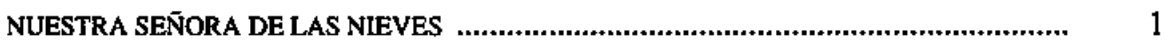

Aficiones y devociones en el antiguo regimen

Hispania Sacra 50 (1998) 


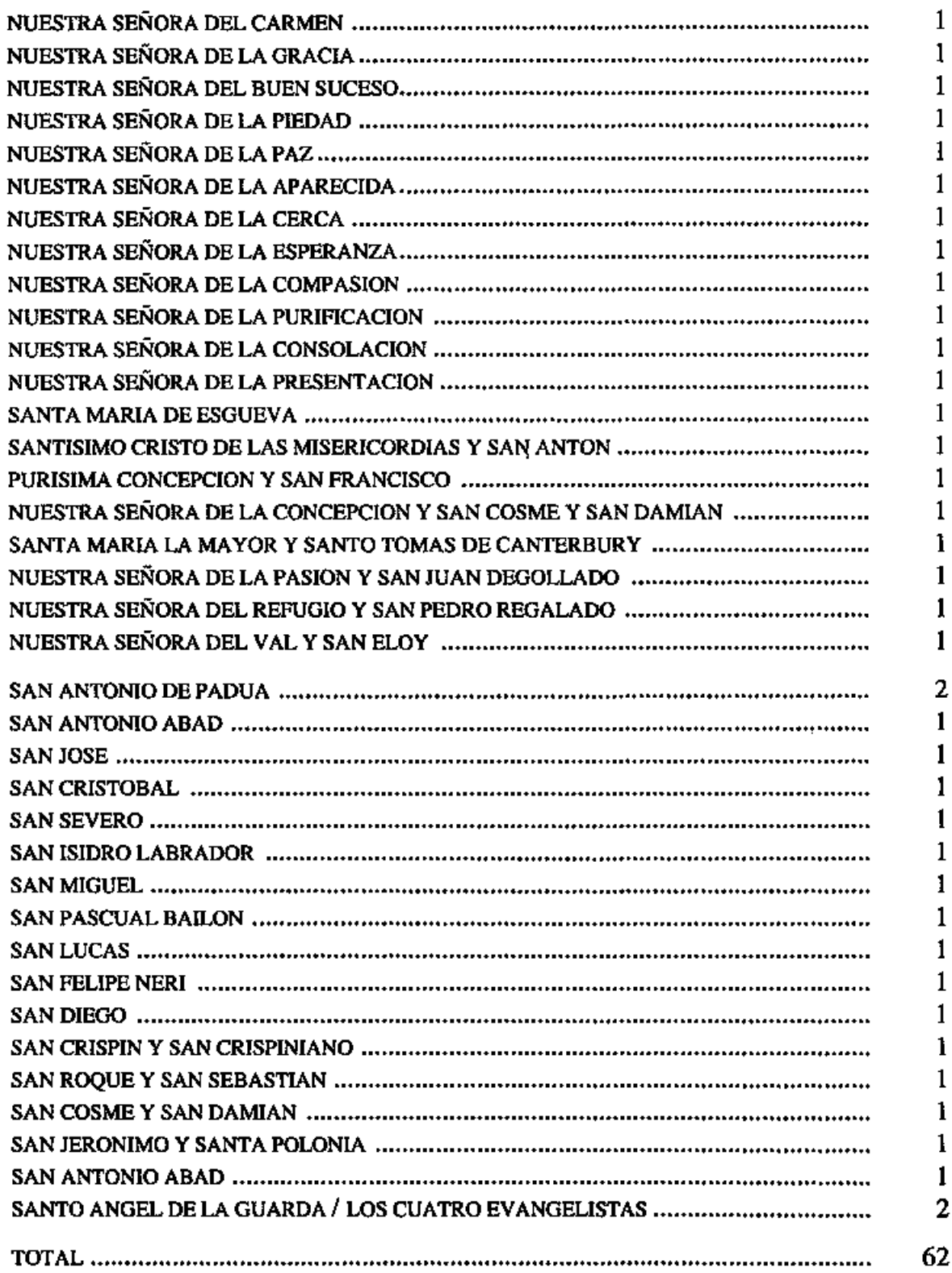

